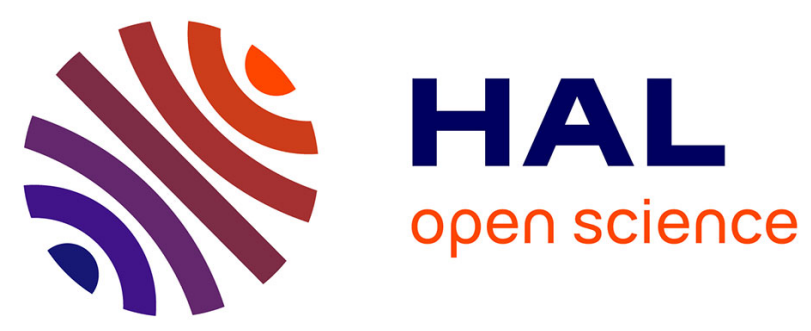

\title{
Flash sintering of cationic conductive ceramics: A way to build multilayer systems
}

\author{
Marie Lachal, Hana El Khal, Didier Bouvard, Jean-Marc Chaix, Renaud \\ Bouchet, Marlu Cesar Steil
}

\section{- To cite this version:}

Marie Lachal, Hana El Khal, Didier Bouvard, Jean-Marc Chaix, Renaud Bouchet, et al.. Flash sintering of cationic conductive ceramics: A way to build multilayer systems. Journal of the American Ceramic Society, 2021, 104 (8), pp.3845-3854. 10.1111/jace.17787 . hal-03334120

\author{
HAL Id: hal-03334120 \\ https://hal.science/hal-03334120
}

Submitted on 3 Sep 2021

HAL is a multi-disciplinary open access archive for the deposit and dissemination of scientific research documents, whether they are published or not. The documents may come from teaching and research institutions in France or abroad, or from public or private research centers.
L'archive ouverte pluridisciplinaire HAL, est destinée au dépôt et à la diffusion de documents scientifiques de niveau recherche, publiés ou non, émanant des établissements d'enseignement et de recherche français ou étrangers, des laboratoires publics ou privés. 


\section{Flash sintering of cationic conductive ceramics: a}

\section{way to build multilayer systems}

Marie Lachal $^{\dagger}$, Hana El Khal ${ }^{\dagger}$, Didier Bouvard $\ddagger$, Jean-Marc Chaix $\ddagger$, Renaud Bouchet ${ }^{\dagger, *}$, Marlu Cesar Steil ${ }^{\dagger, *}$

† Univ. Grenoble Alpes, Univ. Savoie Mont Blanc, CNRS, Grenoble INP, LEPMI, 38000 Grenoble, France.

‡Univ. Grenoble Alpes, CNRS, Grenoble INP, SIMAP, 38000 Grenoble, France.

* E-mail: Renaud.Bouchet@ grenoble-inp.fr

* E-mail: Marlu-Cesar.Steil@grenoble-inp.fr

\section{ABSTRACT.}

Flash Sintering (FS), that allows densifying ceramics at low furnace temperature in a few seconds, requires a reversible electrochemical reaction to enable the current flow through the electrode / material interface. For $\mathrm{Li}^{+}$pure ionic conductors such as $\mathrm{Li}_{1.3} \mathrm{Al}_{0.3} \mathrm{Ti}_{1.7}\left(\mathrm{PO}_{4}\right)_{3}$ (LATP), the best material to ensure this fast charge transfer reaction is a mixed $\mathrm{Li}^{+} / \mathrm{e}^{-}$conductor, e. $g$., $\mathrm{LiCoO}_{2}$ (LCO). This paper demonstrates the feasibility of FS on LCO between two Pt electrodes and on multi-layers systems using LCO or LATP+LCO composite as electrodes. It is shown that a 
composite electrode both allows the flash event to occur and prevents the delamination possibly observed with pure LCO by lowering interfacial stresses

\section{KEYWORDS.}

Flash Sintering, reversible electrochemical reaction, interface, LATP, LCO,

\section{Introduction}

Among Electrical Current Activated Sintering (ECAS) techniques, Flash Sintering (FS) is very effective to densify conductive ceramics in a few seconds at significantly lower temperatures compared to conventional sintering. ${ }^{(1)(2)}$ FS consists of making the current directly flow through the sample without the use of a conductive die. The flash phenomenon is observed as a sudden increase of the current due to a thermal runaway effect of Joule heating, ${ }^{(3)}$ the key point being the increase of electrical conductivity with increasing temperature. A correlated sudden shrinkage and densification is observed.

This recent technique was first reported by Cologna et al. ${ }^{(1)}$ in 2010 who sintered tetragonal yttrium-stabilized zirconia (3YSZ) in less than $5 \mathrm{~s}$ at $850^{\circ} \mathrm{C}$. Since then, numerous papers reported the feasibility of FS on YSZ either tetragonal ${ }^{(1),(4)(6)}$ or cubic, $^{(2),(7)(10)}$ which is now considered as a model material for the flash phenomenon studies. FS has been studied on many other oxides materials such as ionic conductors $\left(\mathrm{Y}_{2} \mathrm{O}_{3},{ }^{(11)}\right.$ Gd-doped ceria, $\left.{ }^{(12)}\right)$; mixed ionic electronic conductors (MIEC) $\left((\mathrm{La}, \mathrm{Sr})(\mathrm{Co}, \mathrm{Fe}) \mathrm{O}_{3},{ }^{(13)} \mathrm{SrTi}_{1-\mathrm{x}} \mathrm{Fe}_{\mathrm{x}} \mathrm{O}_{3-\delta},{ }^{(14)} \quad \mathrm{MnCo}_{2} \mathrm{O}_{4},{ }^{(15)}\right)$; semi-conductors $\left(\mathrm{TiO}_{2},{ }^{(16)} \mathrm{SnO}_{2},{ }^{(17)} \mathrm{ZnO},{ }^{(18)}\right)$; and microcomposites containing $\mathrm{Al}_{2} \mathrm{O}_{3}$ and $\mathrm{ZrO}_{2} \cdot{ }^{(19)}$-(21) Recent reviews more exhaustively reported FS process on different types of materials as well as their phenomenological behavior under a flash event. ${ }^{(22),(23)}$ In the case of pure anionic oxides, the 
conductivity is attributed to oxygen vacancies. The charge transfer between the electronic conductor (i.e. current collectors) and the pure ionic conductor (i.e. ceramic electrolyte) is ensured by a reversible electrochemical reaction between oxygen vacancies and atmospheric $\mathrm{O}_{2}$ occurs at the interface (Eq. 1).

$\frac{1}{2} O_{2(g a s)}+2 e^{-}{ }_{(C C)}+V_{O_{(E l)}} \leftrightarrow O_{O^{X}}{ }_{(E l)}$

Where gas, CC and El stand for gas phase, current collector and ceramic electrolyte, respectively. This electrochemical reaction enables the current flow through the sample and possibly the flash triggering. Platinum current collectors are classically used because they act as catalyst enabling fast reversible electrode reaction at temperature higher than $800{ }^{\circ} \mathrm{C} .{ }^{(24)}$ Another possible way to sinter anionic oxides, such as yttrium-stabilized zirconia, is to employ a mixed electronic / anionic conductor, for example a composite of NiO-8YSZ, in order to build a multilayer system for SOFC application. ${ }^{(25)}$

Regarding pure cationic conductors $\left(\mathrm{Li}^{+}, \mathrm{Na}^{+}, \mathrm{K}^{+}\right.$, etc.), Caliman et al. ${ }^{(26)}$ emphasized that a reversible electrochemical reaction at the electrode / material interface is a mandatory condition for the flash event to occur. Pt electrodes do not allow the flash phenomenon to occur because they are blocking electrodes: no charge transfer reaction between the electrodes and the material is possible. Thus, no current can flow through the interface. This has been well demonstrated by using Ag electrodes instead of Pt electrodes in order to flash sinter the $\mathrm{Na}^{+}$conductor $\beta$-alumina ${ }^{(26)}$ : the charge transfer reaction was in this case operated by means of the $\mathrm{Na}^{+} \leftrightarrow \mathrm{Ag}^{+}$ionic exchange. The only drawback is the contamination of $\mathrm{Na} \beta-\mathrm{Al}_{2} \mathrm{O}_{3}$ by $\mathrm{Ag}^{+}$ions. In their recent paper of flash 
sintering on $\mathrm{Li}^{+}$cationic conductors, ${ }^{(27)}$ the group of Raj also used Ag electrodes, that satisfy this criterion, but they did not comment this choice.

Therefore, to enable the current flow and perform flash sintering of $\mathrm{Li}^{+}, \mathrm{Na}^{+}, \mathrm{K}^{+}$or other ionic conductors, a reversible charge transfer reaction between alkaline cations $\left(\mathrm{Li}^{+}, \mathrm{Na}^{+}\right.$or $\left.\mathrm{K}^{+}\right)$and electrons is necessary. The reversibility of the reaction is important since it involves high kinetics for the electrode reaction. If the reaction is irreversible (i. e. very slow), the flash event will not be easily triggered by DC polarization. To be noted that DC polarization implies a continuous electrochemical transformation at the interfaces (i. e. electrolysis) which may induce strong chemical composition variation near these interfaces, such as darkening of the cathodic surface of a flash-sintered yttrium-doped zirconia pellet (ref. Elizabeth Dickey). Alternatively, the flash event can also be triggered by an AC polarization, with a mean value centered on zero. In that case, a reversible electrochemical reaction will ensure that in average there is almost no chemical composition variation at the interface between the collector and the ceramic, which is a necessary condition for one shot flash sintering of functional systems (electrode/electrolyte/electrode) such as solid-state batteries.

In the field of All Solid-State Li-ion Batteries (ASSLiB), mainly Spark Plasma Sintering (SPS) has been used to shape and sinter entire multi-material systems based on NASICON-type $\mathrm{Li}^{+}$ionic conductors such as $\mathrm{Li}_{1+x} \mathrm{Al}_{\mathrm{x}} \mathrm{Ti}_{2-\mathrm{x}}\left(\mathrm{PO}_{4}\right)_{3}$ (LATP) or $\mathrm{Li}_{1+\mathrm{x}} \mathrm{Al}_{\mathrm{x}} \mathrm{Ge}_{2-\mathrm{x}}\left(\mathrm{PO}_{4}\right)_{3}(\mathrm{LAGP})^{(28)}$ (30) or, more recently, on garnet-based electrolyte $\mathrm{Li}_{7} \mathrm{La}_{3} \mathrm{Zr}_{2} \mathrm{O}_{12}$ (LLZO) with $\mathrm{LiCoO}_{2}$ (LCO) as positive electrode material ${ }^{(31)(32)}$. SPS does not required any charge transfer reaction because the sample is heated by an external source; However, SPS requires a more complex and expensive equipment than FS, as well as a special carbide die which can lead to reduction of some components (the 
active materials (such as LCO) and the electrolyte (e. g. LATP)) in such multimaterial systems. In addition the Flash sintering is generally faster then other electrically assisted sintering processes which may prevent grain growth and chemical interfacial reactivity.

In order to flash sinter $\mathrm{Li}^{+}$ionic conductors, the best electrode materials are mixed $\mathrm{Li}^{+}$/ electronic conductors. In this context, the insertion compound $\mathrm{LiCoO}_{2}$ (LCO) seems appropriate to ensure the charge transfer reaction with the following reversible electrochemical reaction :

$\mathrm{LiCo}^{(+I I I)} \mathrm{O}_{2} \leftrightarrow \mathrm{Li}_{1-x} \mathrm{Co}^{(+I I I / I V)} \mathrm{O}_{2}+x \mathrm{Li}^{+}+e^{-}$

As LCO is a mixed conductor (electronic and $\mathrm{Li}^{+}$), it does not need, a priori, a specific electrode material to be flash sintered because the current can flow through the electrode / material interface directly by means of the electrons of which the conductivity is thermally activated. However, no previous study reported about FS on mixed $\mathrm{Li}^{+}$/ electronic conductors, such as LCO. In addition, a possible way to flash sinter cationic conductors such as LATP is to assemble a multi-layer system composed of the cationic conductor sandwiched between two mixed electronic/ionic conductors.

To pave the way to produce functional systems, our aim is to show the feasibility to flash sinter $\mathrm{Li}^{+}$cation conductor using active material for batteries based on the reversible electrochemical reaction at their interfaces. Firstly, the Flash Sintering of a mixed electronic / $\mathrm{Li}^{+}$ionic conductor (herein LCO) is demonstrated, which allowed us use it as electrode material, and conduct FS on multi-layer systems based on pure cationic conductor $\mathrm{Li}_{1+\mathrm{x}} \mathrm{Al}_{\mathrm{x}} \mathrm{Ti}_{2-\mathrm{x}}\left(\mathrm{PO}_{4}\right)_{3}$ (LATP).

\section{Experimental methods}

\subsection{Sample processing}


Industrial $\mathrm{LiCoO}_{2}$ (labelled LCO) and $\mathrm{Li}_{1.3} \mathrm{Al}_{0.3} \mathrm{Ti}_{1.7}\left(\mathrm{PO}_{4}\right)_{3}$ (labelled LATP) powders were ground by planetary ball milling (Pulverisette 7 classic line, Fristch) at $500 \mathrm{rpm}$ for $5 \mathrm{~h}$ in a stainless steel bowl with balls of diameter $5 \mathrm{~mm}$. A mix containing $40 \mathrm{wt} \%$ of LCO (28 vol\%) +60 wt $\%$ of LATP (72 vol\%) was fabricated by planetary ball milling at $700 \mathrm{rpm}$ for 15 min to make composite electrodes.

The powder mix was compacted first uniaxially under $40 \mathrm{MPa}$ in a die of diameter $8 \mathrm{~mm}$, then isostatically under $250 \mathrm{MPa}$. Green compacts with a relative density of $60 \%$ TD for LCO (theoretical density $\left.=5.05 \mathrm{~g} \cdot \mathrm{cm}^{-3}\right)^{(28)}$ and of $63 \%$ TD for LATP (theoretical density $=2.92 \mathrm{~g} . \mathrm{cm}^{-}$ $\left.{ }^{3}\right)^{(34)}$ were obtained. The green compacts were around $8 \mathrm{~mm}$ in diameter $\left(\sim 0.45 \mathrm{~cm}^{2}\right.$ in area) and around $3 \mathrm{~mm}$ in thickness after isostatic compaction. Current densities, electric fields and effective conductivities mentioned in the following were calculated from applied voltage, measured current and initial compact dimensions. As a comparison, LCO and LATP pellets were densified by conventional sintering (CS) at $1040{ }^{\circ} \mathrm{C}$ for $2 \mathrm{~h}$ and $1000^{\circ} \mathrm{C}$ for $1 \mathrm{~h}$ respectively, at $5{ }^{\circ} \mathrm{C} /$ min under argon atmosphere. The geometrical density of the sintered pellets was $\left(95^{ \pm} 1\right) \% \mathrm{TD}$.

Two multi-layer systems were studied.

\section{1) Multi-layer System 1 (LCO/LATP/LCO)}

The ball-milled LCO and LATP powders were placed in the $8 \mathrm{~mm}$ diameter die: $0.2 \mathrm{~g}$ of LCO, then $0.3 \mathrm{~g}$ of LATP then $0.2 \mathrm{~g}$ of LCO. Each layer was slightly pressed to ensure a flat top surface before pouring the next powder layer. In this system, the mixed electronic / ionic conductor LCO played the role of the electrode. This stacking was directly compacted uniaxially and isostatically as previously described. The total thickness of the green compact System 1 was $7.2 \mathrm{~mm}$.

\section{2) Multi-layer System 2 (composite LCO+LATP / LATP / composite LCO+LATP)}


In this case, the stack was $0.2 \mathrm{~g}$ of $40 \mathrm{wt} \%$ of composite (LCO (28 vol\%) $+60 \mathrm{wt} \%$ of LATP (72 vol\%)) / 0.3 g of LATP / 0.2 g of 40 wt $\%$ of composite (LCO (28 vol\%) + 60 wt \% of LATP (72 vol\%)), where the composite plays the role of the electrode. The same process as System 1 was used for compaction. The thickness of the green compact System 2 is $8.4 \mathrm{~mm}$. The post-flash density and the accurate thickness of each layer were determined geometrically from SEM cross sections. A theoretical density of 3.51 g. $\mathrm{cm}^{-3}$ was used for the composite mixture.

\subsection{Flash sintering methodology}

To ensure a uniform electrical contact distribution and collection, a shiny platinum layer of about 600-700 nm was deposited by PVD on the top and bottom surfaces of green compacts. Green samples were placed between platinum disk-shaped current collectors in the experimental setup described in a previous paper. ${ }^{(2)}$ Platinum grids were added between the sample and the Pt current collectors to prevent them sticking together. Then, the setup was placed in the furnace with argon flux as the atmosphere. The oxygen partial pressure was measured with an oxygen sensor to be around $10^{-5}$ bar in every experiment. The FS was performed under isothermal conditions, ${ }^{(2),(20),(35)}$ i.e. an electric field $\mathrm{E}_{0}$ was applied to a sample while the furnace temperature $\mathrm{T}_{0}$ was kept constant. The flash onset was observed after a delay time, which depends on the electric field $\mathrm{E}_{0}$ and on the green sample effective conductivity. The furnace was heated up to the sample pre-heating temperature $\left(T_{0}\right)$ for which the green sample conductivity was sufficient to trigger the flash (around $10^{-3}{\mathrm{~S} . \mathrm{cm}^{-1}}$ for $\left.100 \mathrm{~V} . \mathrm{cm}^{-1}\right) .{ }^{(20),(36)}$ To determine $\mathrm{T}_{0}$, the green compact resistance was measured by electrochemical impedance spectroscopy every $50{ }^{\circ} \mathrm{C}$ from ambient temperature to $500{ }^{\circ} \mathrm{C}$ at $1.7^{\circ} \mathrm{C} / \mathrm{min}$ and stabilized for $90 \mathrm{~min}$ at each step. A thermocouple was placed in the setup close to the sample to precisely measure the temperature. Once the threshold temperature $\mathrm{T}_{0}$ was 
reached, the electric field $E_{0}$ was applied. AC voltage was provided by a Pacific Smart Source 115ASX AC power generator connected to the sample holder and controlled by the UPC Manager V.1.4 software. We used alternative current (AC) to avoid undesirable electrode reaction, especially under high electrical fields. The amplitude of the applied AC electric field Eo ranged from 75 to $100 \mathrm{~V} \cdot \mathrm{cm}^{-1}$. The AC frequency was $1 \mathrm{kHz}$. To limit the thermal runaway generated by the increasing dissipated power, the maximum electrical current density was fixed at $4 \mathrm{~A} . \mathrm{cm}^{-2}$. This equipment has been implemented by Cordier et al. ${ }^{(37)}$

\subsection{Sample characterization}

The sample conductivity was measured at various temperatures by impedance spectroscopy on the LCO pellet densified by conventional sintering and on green samples before and after FS. A Solartron 1260 frequency analyzer from $100 \mathrm{~Hz}$ to $10 \mathrm{MHz}$ with voltage amplitudes varying from $20 \mathrm{mV}$ to $150 \mathrm{mV}$ depending on the global resistance was used for this purpose. Measurements were recorded with the Zplot software and data (Nyquist diagrams) were analysed with the Zview software (Scribner Associates Incorporated). The sample structure and purity (powders before and after ball milling, as well as CS pellets, green samples and FS pellets) were analysed by X-ray diffraction (XRD). Data were collected from a PANalyticalX'Pert Pro MPD diffractometer using

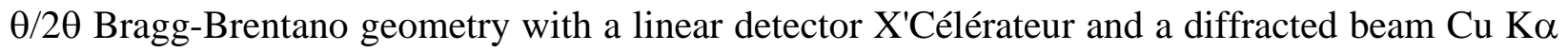
radiation $\left(\lambda_{1}=1.5406 \AA\right.$ and $\left.\lambda_{2}=1.5444 \AA\right)$. The microstructure was examined using a Field Emission Gun SEM (Zeiss Ultra 55) on powders, and on fractured and polished cross sections of the FS pellets (LCO and multi-materials). Carbon flash on the sample surface completed with a brushstroke of silver ink on the borders was used for the surface metallization. EDS analyses and maps (QUANTAX EDS from BRUCKER equipped with an SDD detector, ESPRIT software) 
were performed on multi-layer materials to distinguish the elements belonging to LCO and LATP compounds.

\section{RESULTS AND DISCUSSION.}

Fig. 1 schematises the FS experiment on a LCO green sample. LCO is a mixed conductor whose intrinsic conductivity is both ensured by $\mathrm{Li}^{+}$ions and electrons (

(a)

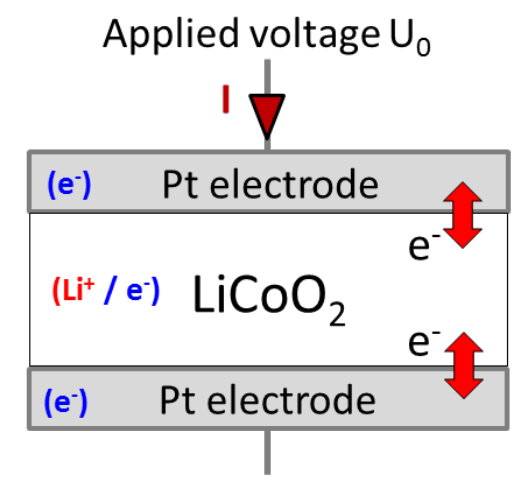

(c)

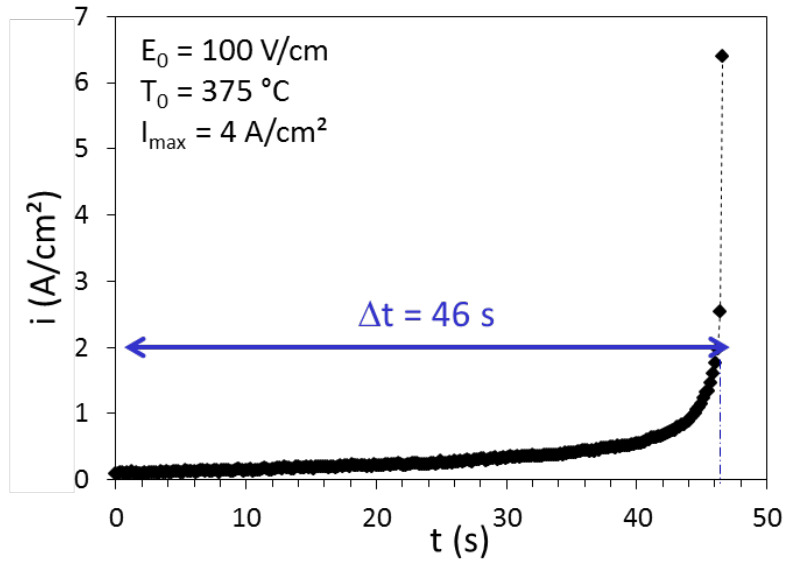

(b)

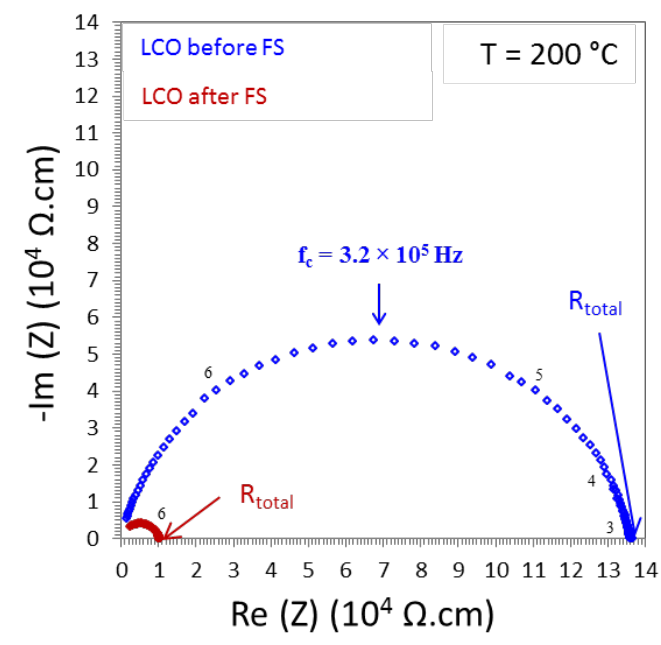

(d)

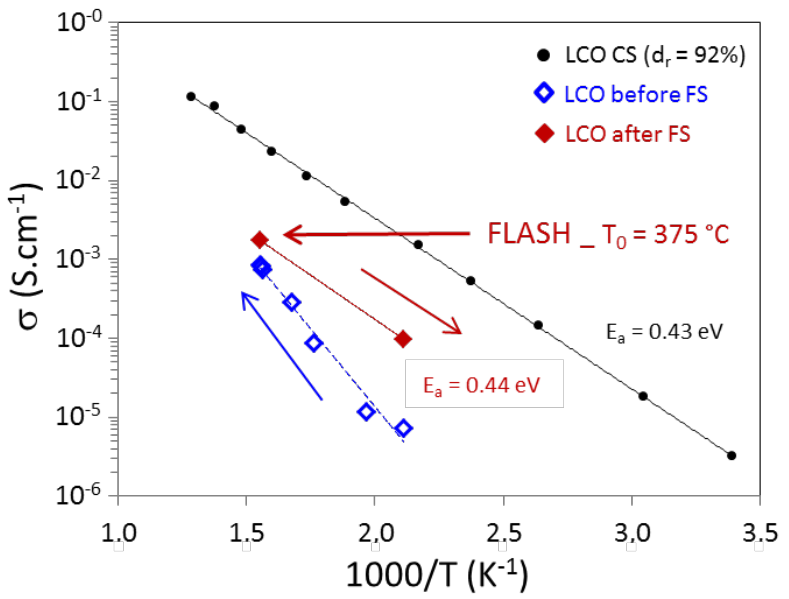


Fig. 1-a). This is represented by a single semi-circle in the impedance diagram at $200{ }^{\circ} \mathrm{C}$ (

(a)

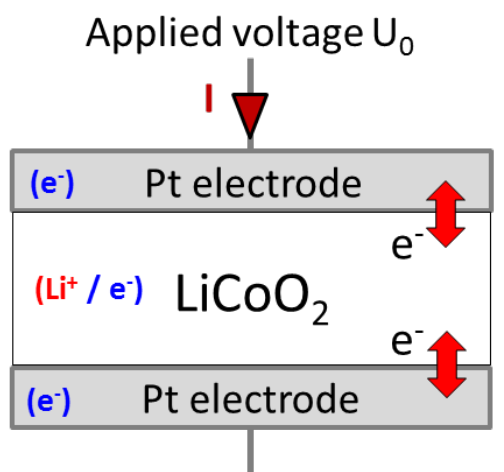

(c)

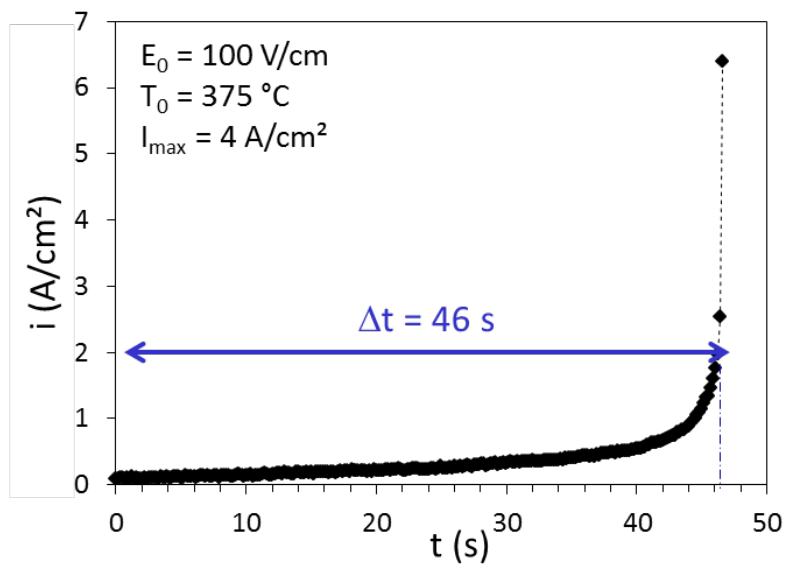

(b)

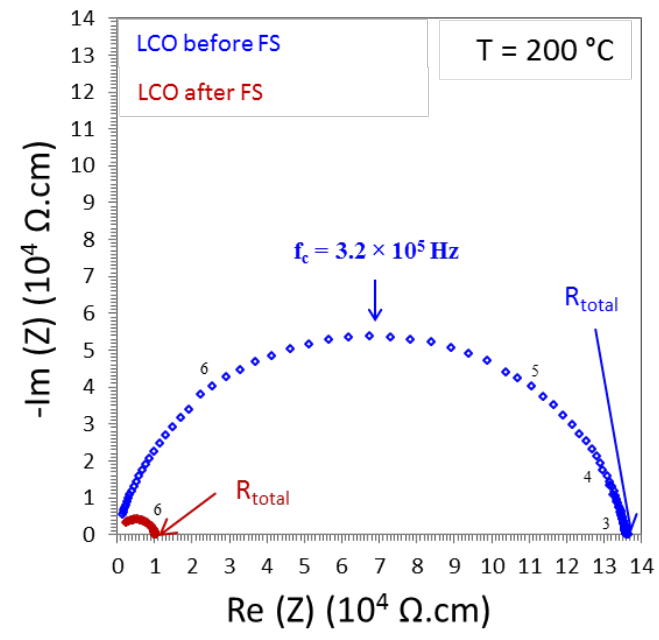

(d)

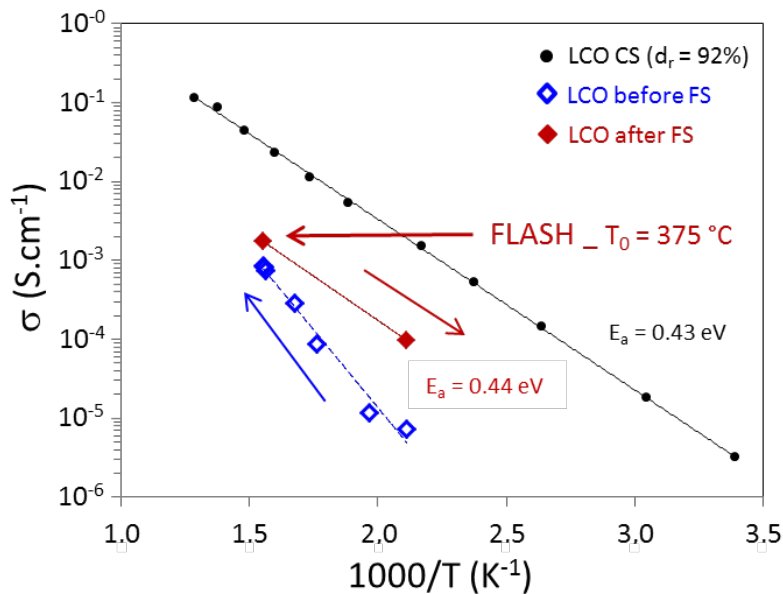

Fig. 1-b, blue diamonds) with a characteristic frequency of $3.2 \times 10^{5} \mathrm{~Hz}$, where the charge transfer reaction with the Pt electrodes is not visible at low frequency. In this case, the current can flow through the electrode / material interface directly thanks to electrons, opening the possibility for a flash phenomenon to occur, whatever the electrodes used (herein classical Pt electrodes). Indeed, there is no need for a an interfacial electrochemical reaction to enable the current flow through the green sample. The only necessary condition for the flash to happen is a thermally activated conductivity. 
(a)

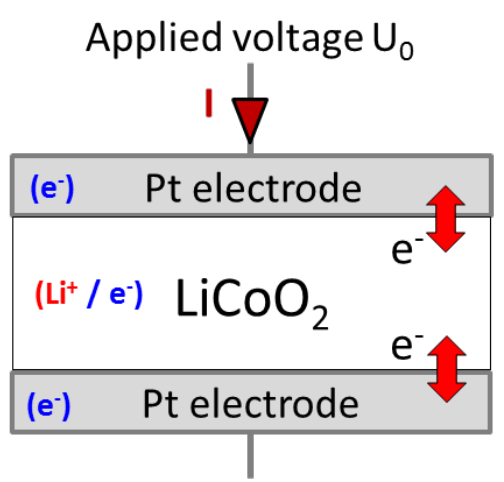

(c)

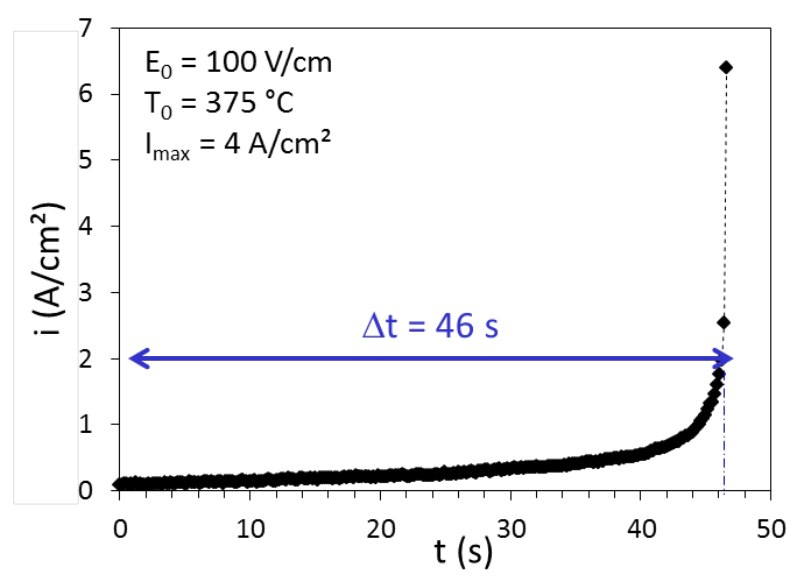

(b)

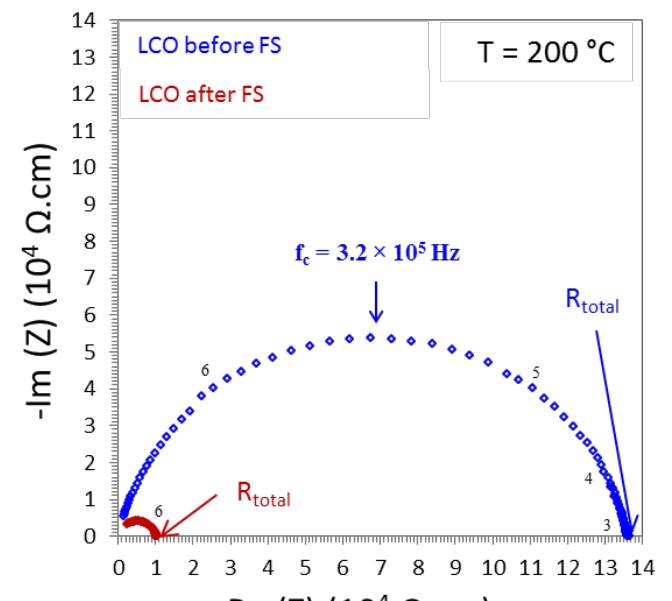

(d)

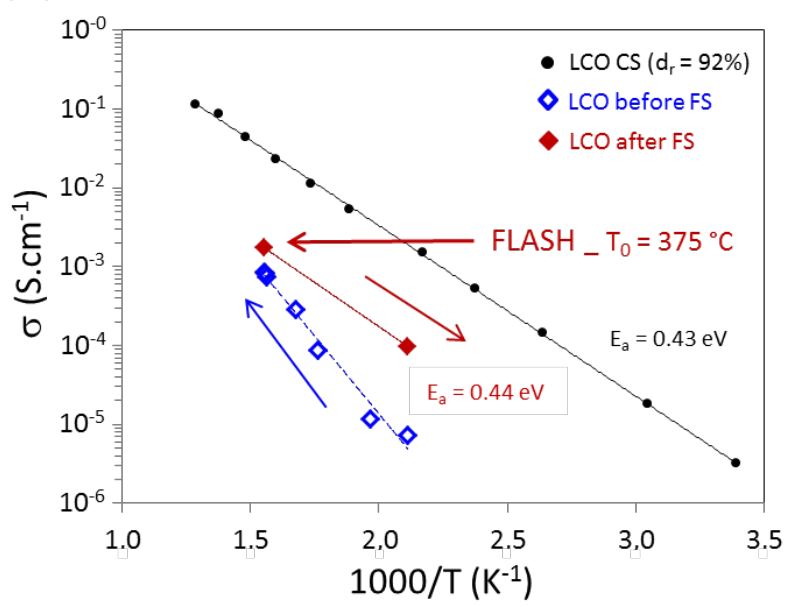

Fig. 1. FS on LCO mixed conductor: (a) Scheme of the cell and charge carriers exchange; (b) Impedance diagram (Nyquist plot) at $200{ }^{\circ} \mathrm{C}$ before and after FS on LCO sample; (c) Average current density variation under $100 \mathrm{~V} \cdot \mathrm{cm}^{-1}$ at $375^{\circ} \mathrm{C}$ (isothermal); (d) Arrhenius plots of the green LCO sample before (blue diamonds) and after (red diamonds) FS compared to the LCO pellet sintered by conventional sintering (black dots). 
(a)

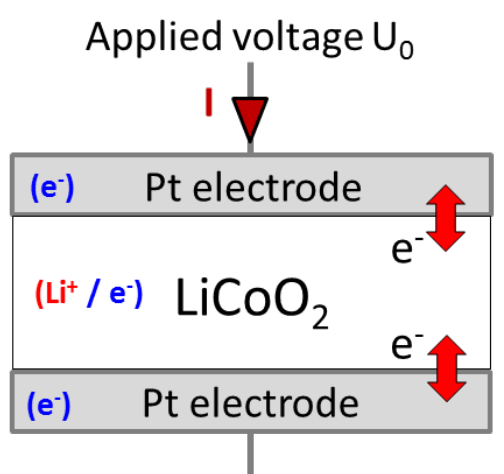

(c)

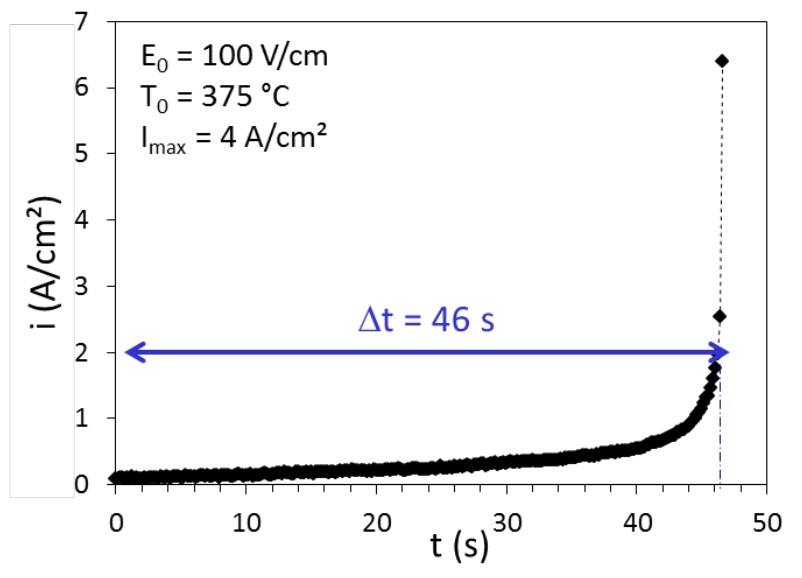

(b)

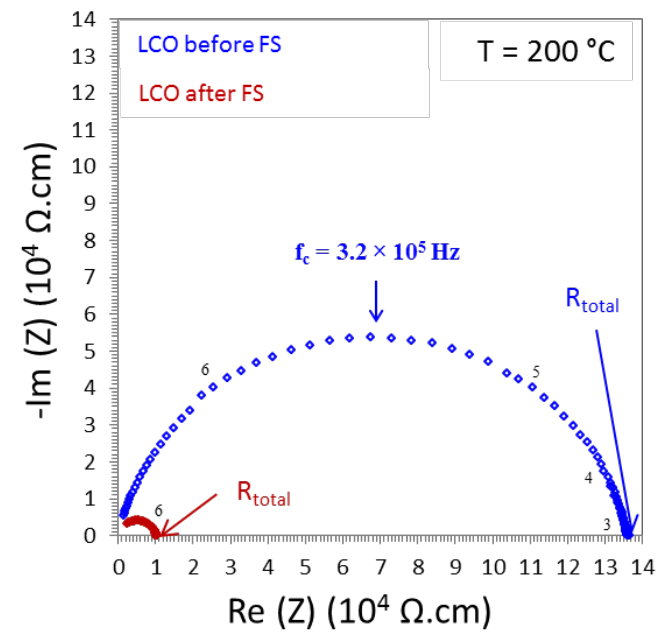

(d)

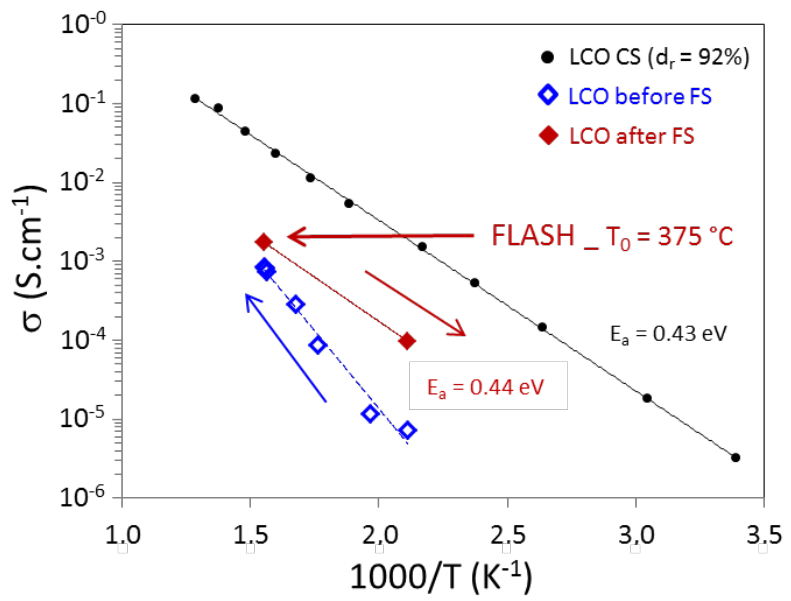

Fig. 1-c, under isothermal conditions at $\mathrm{T}_{0}=375^{\circ} \mathrm{C}$ (temperature at which the conductivity is 1 $\left.\mathrm{mS} . \mathrm{cm}^{-1}\right)$, a current flash was observed after a delay time $(\Delta \mathrm{t}=46 \mathrm{~s})$ following the application of an AC electric field $E_{0}=100$ V.cm ${ }^{-1}$ between the Pt electrodes. The current suddenly increased in 1 or $2 \mathrm{~s}$ up to the pre-set limit $\mathrm{I}_{\max }$. Although the pre-set current density is $4 \mathrm{~A} \cdot \mathrm{cm}^{-2}$, a current spike is observed at 6.5 A.cm², because of the non-zero response time of the power generator (of the order of $1 \mathrm{~s}) .{ }^{(2)}$ It was during this short period that fast densification (shrinkage) occurred. ${ }^{(19),(20)}$ However, depending on the temperature reached, the densification can be more or less effective. In this case, the geometrical density of the LCO green sample increased from (60 \pm 1$) \%$ to (65 \pm 1)\% instead of $95 \%$ in conventional sintering at $1040{ }^{\circ} \mathrm{C}$ for $2 \mathrm{~h}$. 

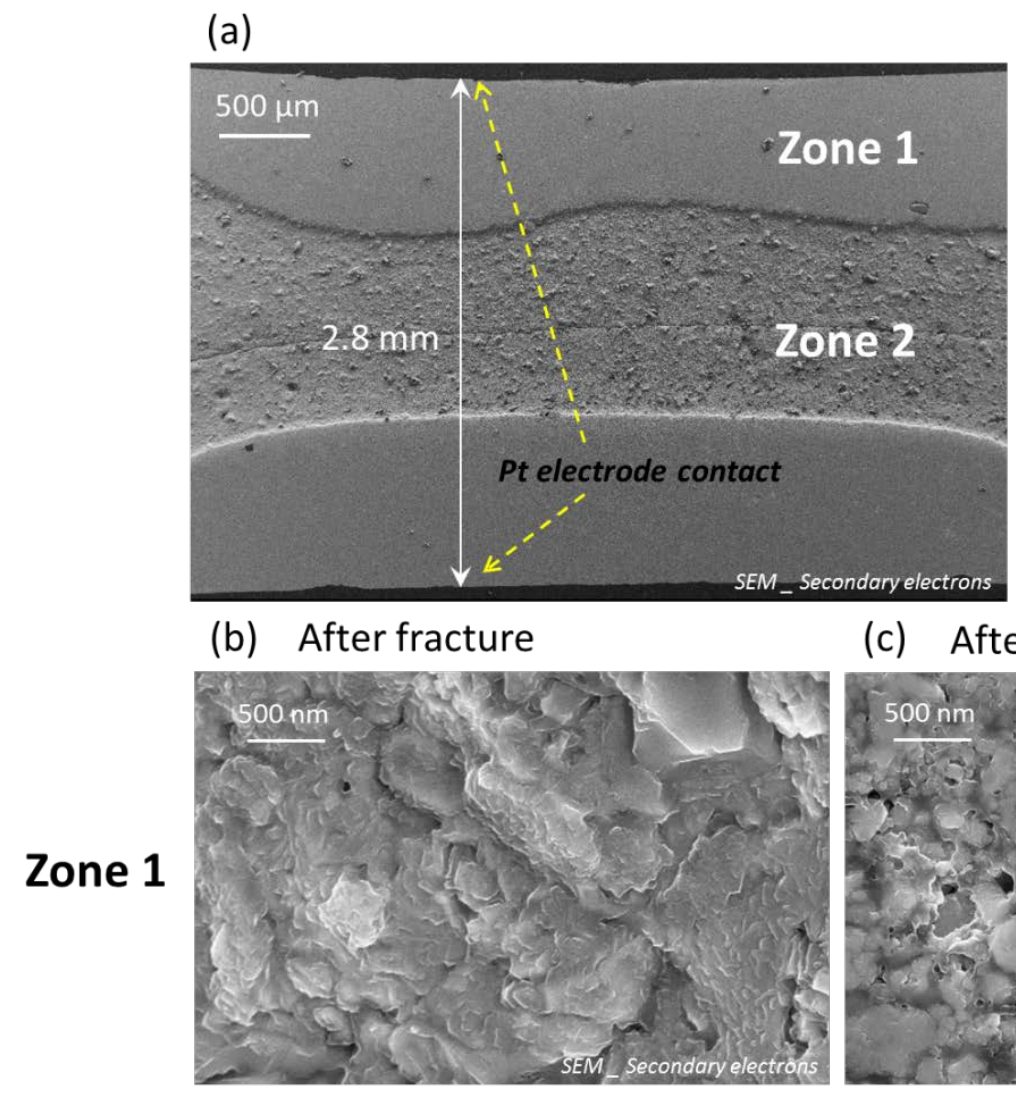

(c) After polishing

(d) After fracture
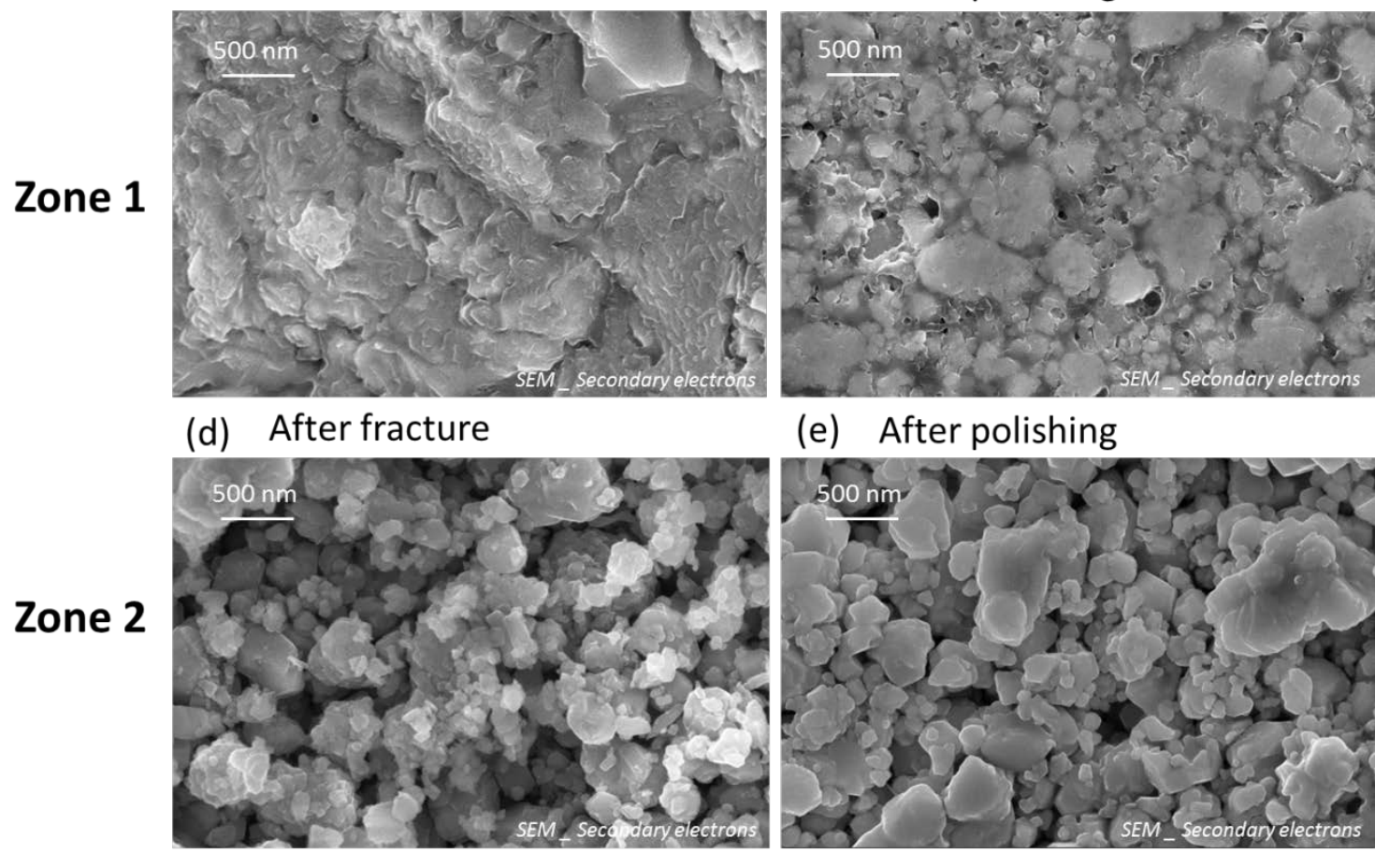

(e) After polishing

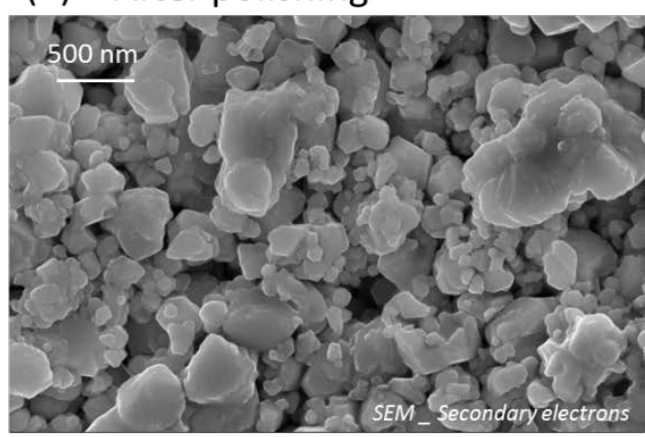

Fig. 2. SEM image of the LCO pellet after Flash Sintering: (a) Overall polished cross section showing two zones: Zone 1 in contact with Pt electrodes (b) after fracture and (c) after polishing and Zone 2 in the center (d) after fracture and (e) after polishing. 
Interestingly, the SEM image of the sample cross-section (Fig. 2-a) shows two different zones: Zone 1 composed of the two sample layers in contact with Pt electrodes and Zone 2 in the center part of the pellet. On magnified SEM images, it is clear that Zone 1 after fracture (Fig. 2-b) appears dense with almost melted regions. On the SEM images after polishing (Fig. 2-c), a certain amount of porosity is observed, and the grain size seems rather similar to the ones in the Zone 2 but imbedded in a glassy phase. On the opposite, Zone 2 seems to not be sintered at all, as no grain boundaries appear neither on the SEM images after fracture (Fig. 2-d) nor on the SEM images after polishing (Fig. 2-e). This suggests a strong temperature gradient across the sample that could be due to local overheating resulting from the contact resistance between the material and the $\mathrm{Pt}$ electrodes. To improve the final density as well as the homogeneity of the microstructure, an optimization of the FS conditions is required, for instance, a higher pre-set intensity $\mathrm{I}_{\max }$ hold for a certain time. Nevertheless, a significant impact on the conductivity was observed, especially at $200^{\circ} \mathrm{C}$, where the conductivity increases from almost one order of magnitude from $7.4 \times 10^{-6}{\mathrm{~S} . \mathrm{cm}^{-}}^{-}$ 
(a)

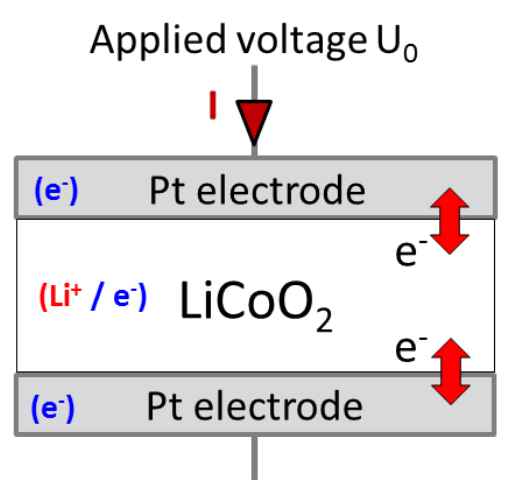

(c)

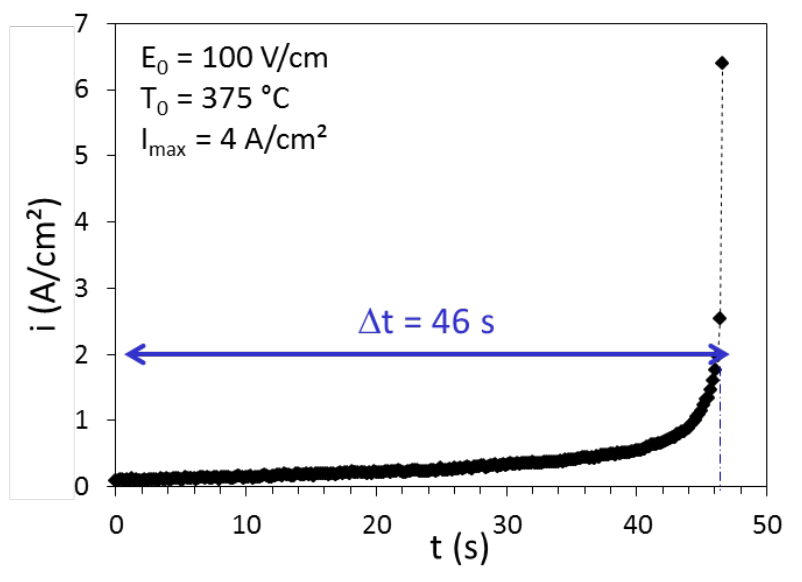

(b)

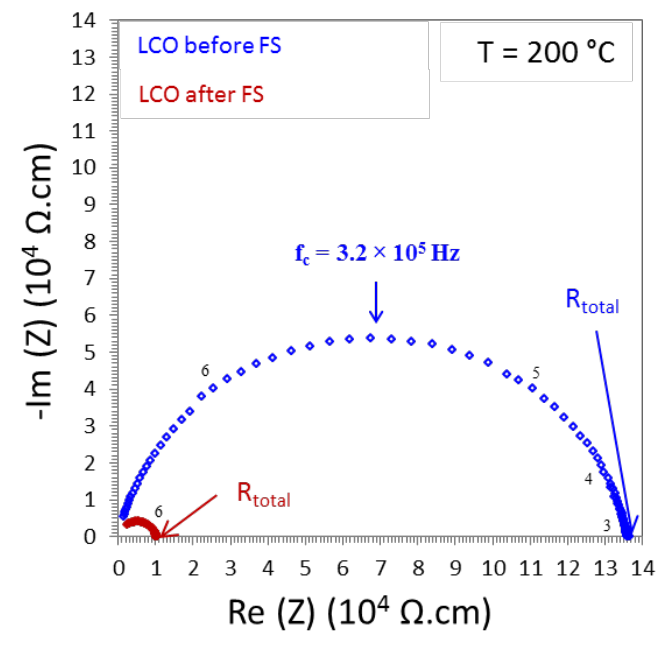

(d)

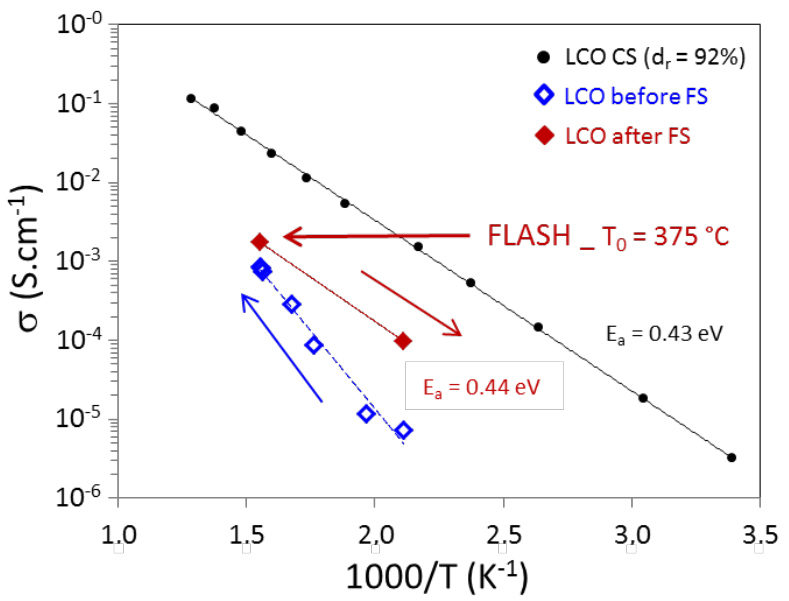

Fig. 1-d). Activation energy after FS is approx. $0.44 \mathrm{eV}$ and is very close to the one of the sintered pellet $(0.43 \mathrm{eV})$. The high resistivity before FS is due to poor grain-to-grain contact. ${ }^{(36)}$ ${ }^{(38)}$ The conductivity enhancement is the result of interparticle necks formation during FS even if it remained one order of magnitude below the conductivity obtained for conventionally sintered pellet, due to high residual porosity especially in the centre of the pellet (Zone 2). ${ }^{(39)}$. These results demonstrate that FS can occur for $\mathrm{LCO}$, a mixed $\mathrm{e}^{-} / \mathrm{Li}^{+}$, between classical platinum electrodes, without electrochemical reaction between the electrodes and the material. 
In the case of LATP, which is a pure $\mathrm{Li}^{+}$ionic conductor, a reversible electrochemical reaction is mandatory. With two platinum electrodes, no charge transfer reaction was expected between electrons and $\mathrm{Li}^{+}$ions (Fig. 3-a). Indeed, at $450{ }^{\circ} \mathrm{C}$, even submitted to $200 \mathrm{~V} . c m^{-1}$ during $30 \mathrm{~min}$, no current flow (and consequently no flash phenomenon) was observed in LATP (Fig. 3-b), in spite of the significant effective conductivity of the LATP green body $\left(\sigma_{\text {eff }}=1.6 \times 10^{-3}{\mathrm{~S} . \mathrm{cm}^{-1}}^{-1}\right)$ at this temperature.

(a)

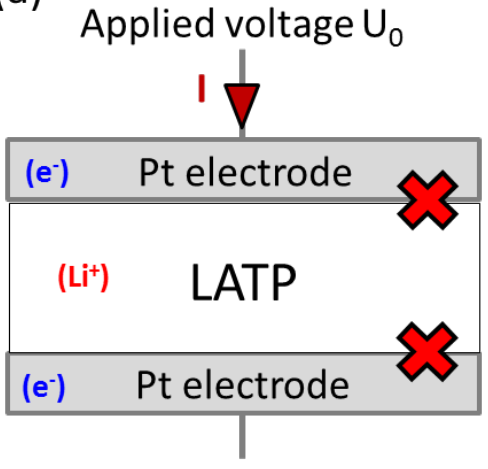

(b)

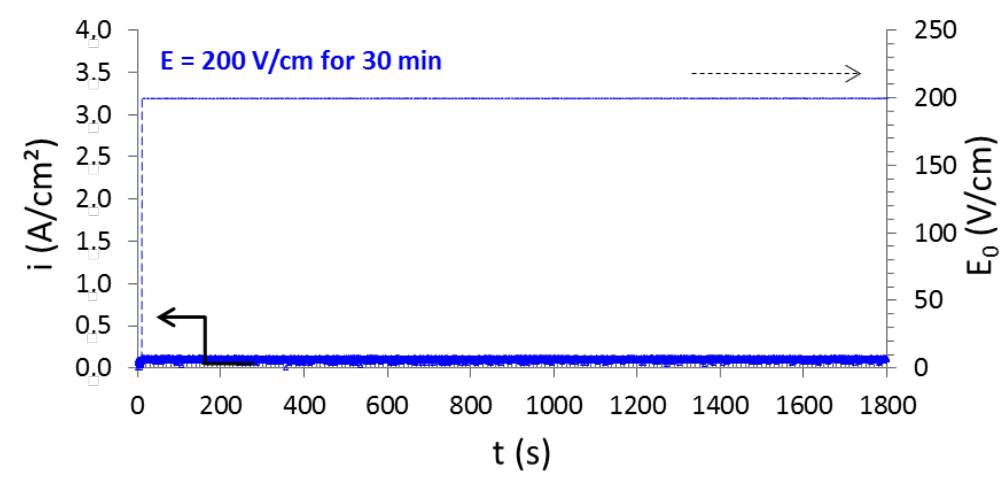

Fig. 3. FS attempt on LATP ionic conductor using Pt current collector: (a) Scheme of the cell and charge carriers exchange; (b) Average current density variation under 200 V.cm ${ }^{-1}$ at $450{ }^{\circ} \mathrm{C}$ (isothermal) for 30 minutes. 
Our first experiments demonstrated that FS was possible for the mixed $\mathrm{Li}^{+} / \mathrm{e}^{-}$conductor LCO (

(a)

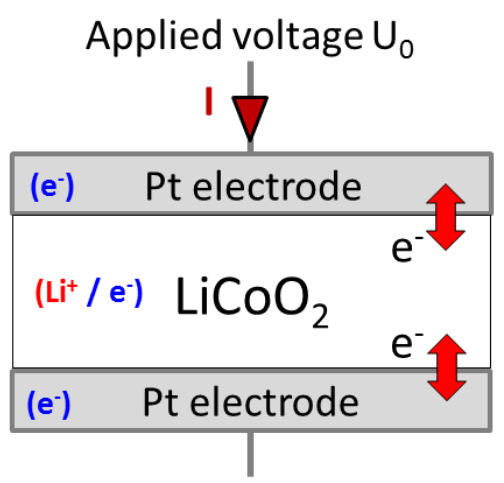

(c)

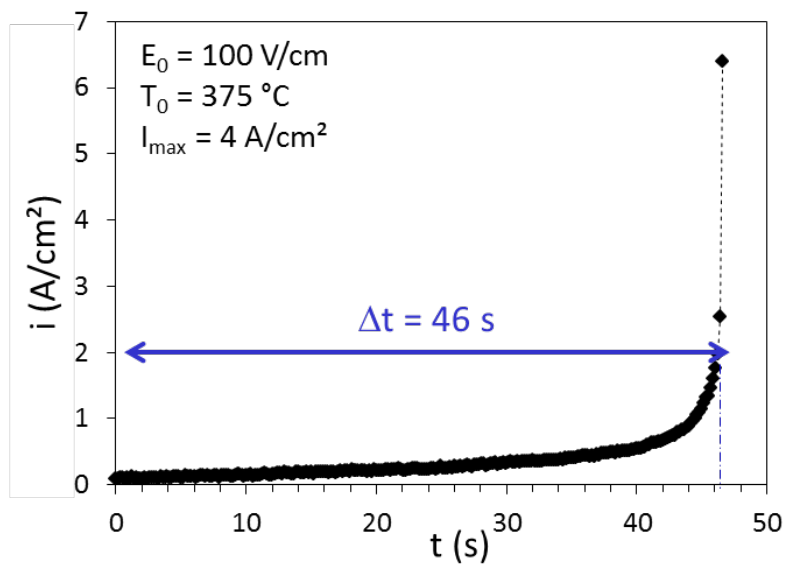

(b)

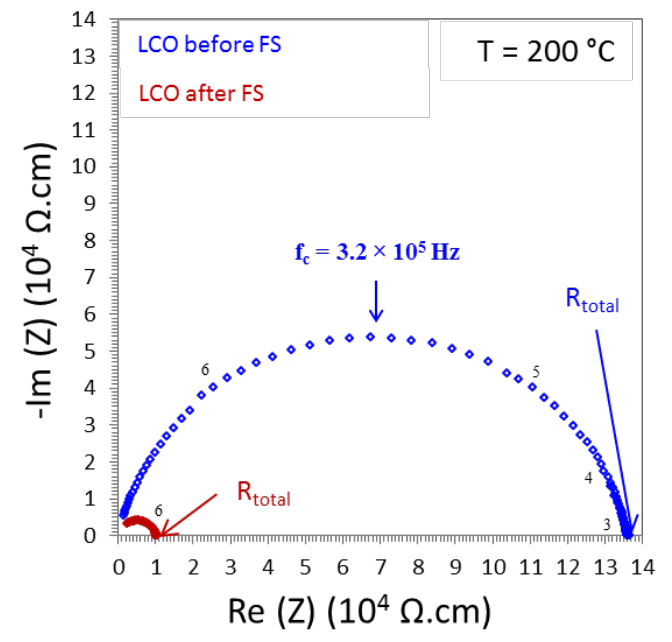

(d)

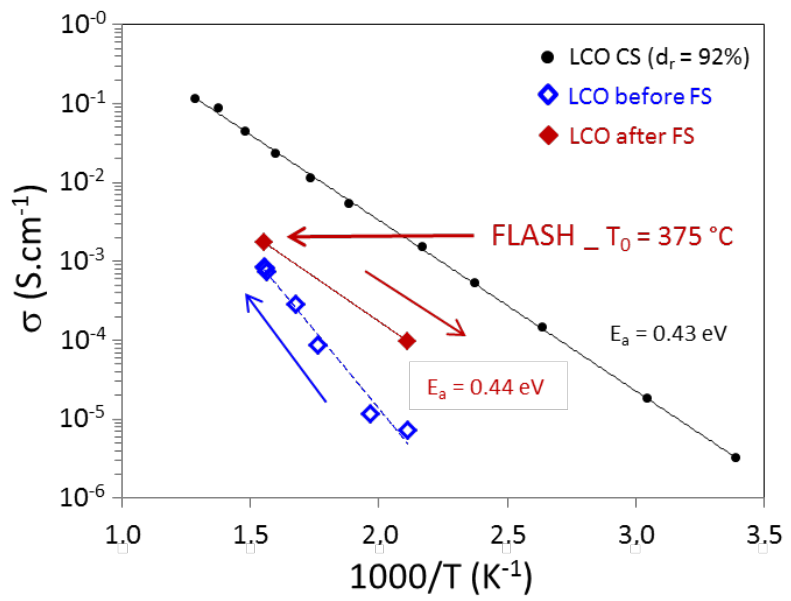

Fig. 1) and knowing that $\mathrm{LCO}$ and LATP can exchange $\mathrm{Li}^{+}$ions via a reversible electrochemical reaction (Eq.2), two configurations of multi-layer systems using LCO or LATP+LCO composite as electrodes and LATP as electrolyte were tested.

Multi-layer System 1 consisted of a green LATP ionic conductor layer sandwiched between two LCO green layers as described in the Experimental Part. As in previous experiments, the system was placed between two Pt electrodes (Fig. 4-a), that acted as current collectors (c.c.). LCO was expected to play the role of reversible electrode. Indeed, by applying an electric field of only 75 V.cm ${ }^{-1}$ at a $\mathrm{T}_{0}=375^{\circ} \mathrm{C}$, a flash was triggered after a delay time of $23 \mathrm{~s}$ (Fig. 4-a). The current efficiently flowed through both LCO, LATP and their interfaces. Thereby, this result highlights 
the feasibility of FS on multi-material systems by using appropriate electrode materials, following our previous work on $\mathrm{Na} \beta$-alumina. ${ }^{(25)}$

(a)

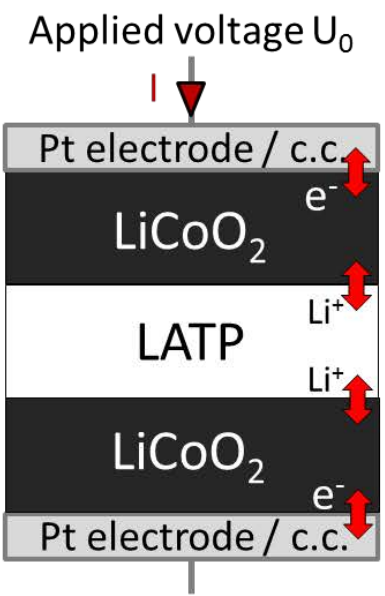

(c) (b)

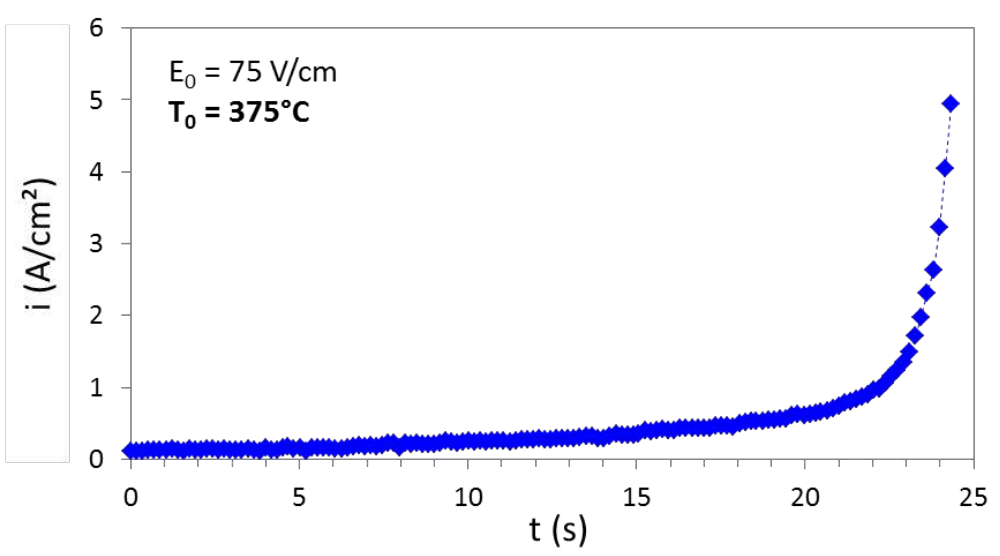

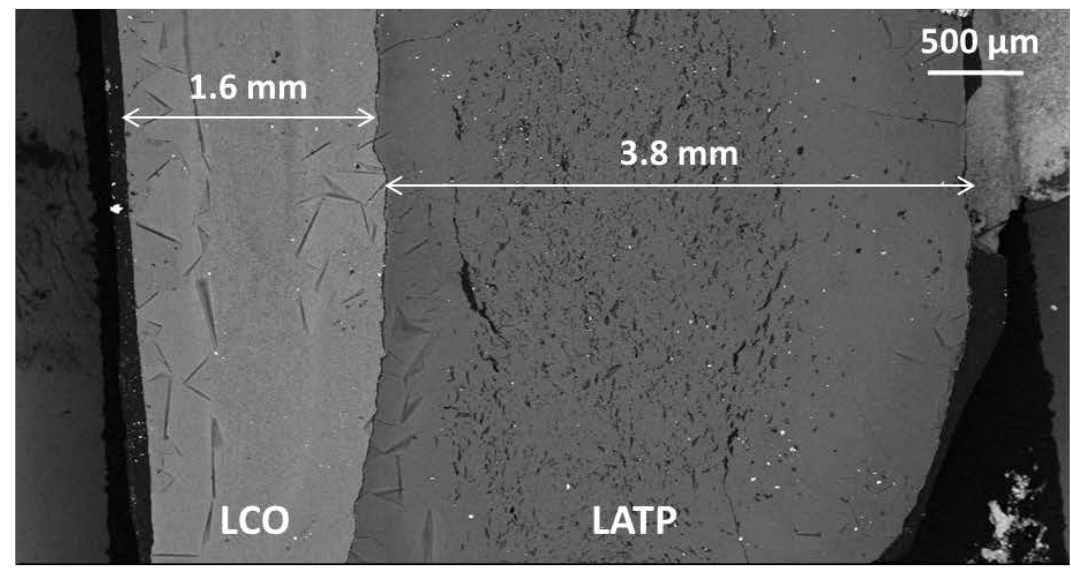

(d)

(e)

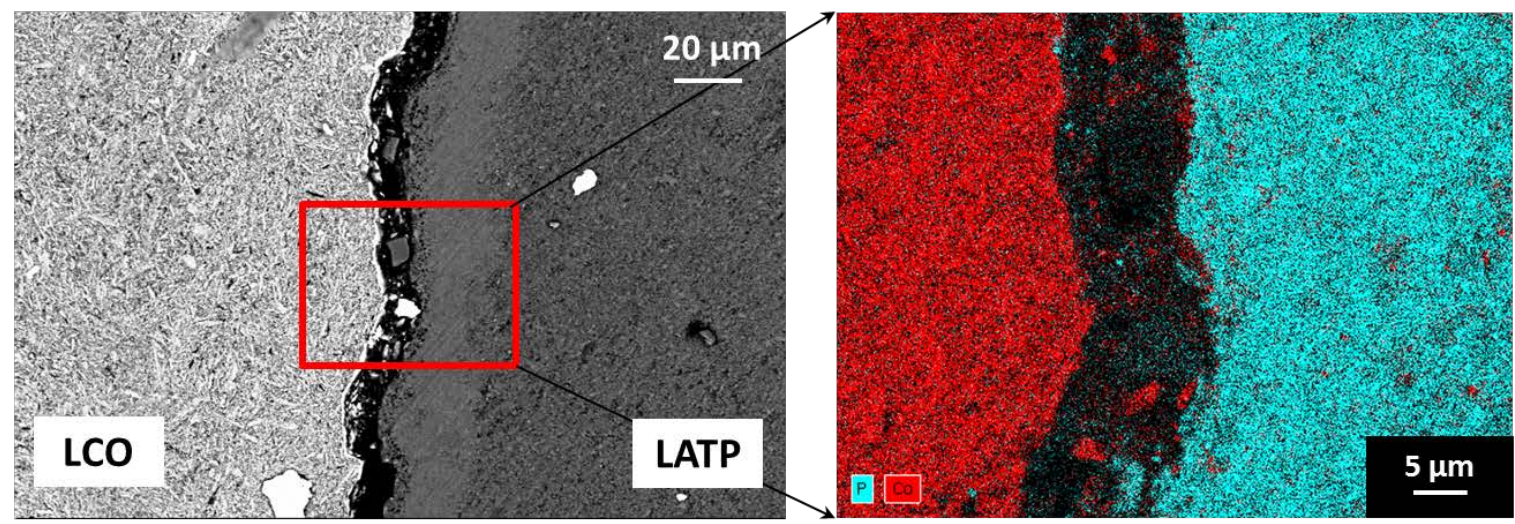

Fig. 4. FS on System 1: LCO / LATP / LCO: (a) Scheme of the cell and charge carrier exchange;

(b) Current density vs. time under 75 V.cm ${ }^{-1}$ at $\mathrm{T}_{0}=375^{\circ} \mathrm{C}$ (isothermal); (c) SEM image of the 
LCO / LATP cross section (BSD - 15 kV); (d) SEM image of the LCO / LATP interface at higher magnification; (e) EDX map of phosphorus (blue) and cobalt (red).

The microstructure of the system was observed by SEM (Fig. 4-c and d) and element maps were performed by EDX (Fig. 4-e). Associated to the flash occurrence, a densification is noticed on System 1 . The relative LATP density, calculated from thickness measurement on the cross section SEM image (Fig. 4-c), increased from 63\% (overall density of the green body) to $74 \%$ after FS. However, SEM images display a heterogeneous microstructure of LATP with large pores in the middle of the pellet (Fig. 4-c) and a denser part in the vicinity of LCO (Fig. 4-d). This could again be associated to a thermal gradient, due to either contact resistances, as in the case of LCO, or charge transfer resistance due to eq. 2, which would lead to a higher Joule dissipation at the LCO/LATP interface. The LCO layer (left side on Fig. 4-e) displays a small densification (66\% after FS), close to our previous experiment with LCO only sintered by FS. Fig. 4-d shows a fracture between LCO and LATP layers, leading to delamination of the multi-layer system. This fracture, which cannot be completely explained by the relatively small difference in thermal expansion coefficients between LCO $\left(\sim 13 \times 10^{-6} /{ }^{\circ} \mathrm{C} \text { over } 50-400{ }^{\circ} \mathrm{C} \text { temperature range }\right)^{(40)}$ and LATP $(\sim$ $11.2 \times 10^{-6} /{ }^{\circ} \mathrm{C}$ over $50-400{ }^{\circ} \mathrm{C}$ temperature range $)^{(41)}$ reveals a weak interface, with low interfacial bounding between the 2 layers. In the present work, the layers were formed by pouring the second powder on the slightly pressed first powder, as explained in the experimental methods section. Although this process is suitable for electrical contacts which give rise to the flash phenomenon, it does not ensure the formation of a mechanically strong interface, so that the mechanical optimization of interfaces will be an important issue for future works. The element mapping (Fig. 4-e) shows a straight delimitation apart from the interfacial fracture between the cobalt from LCO 
and phosphorus from LATP, which suggests no significant inter-diffusion of LCO and the LATP elements at least at the micron-scale. 


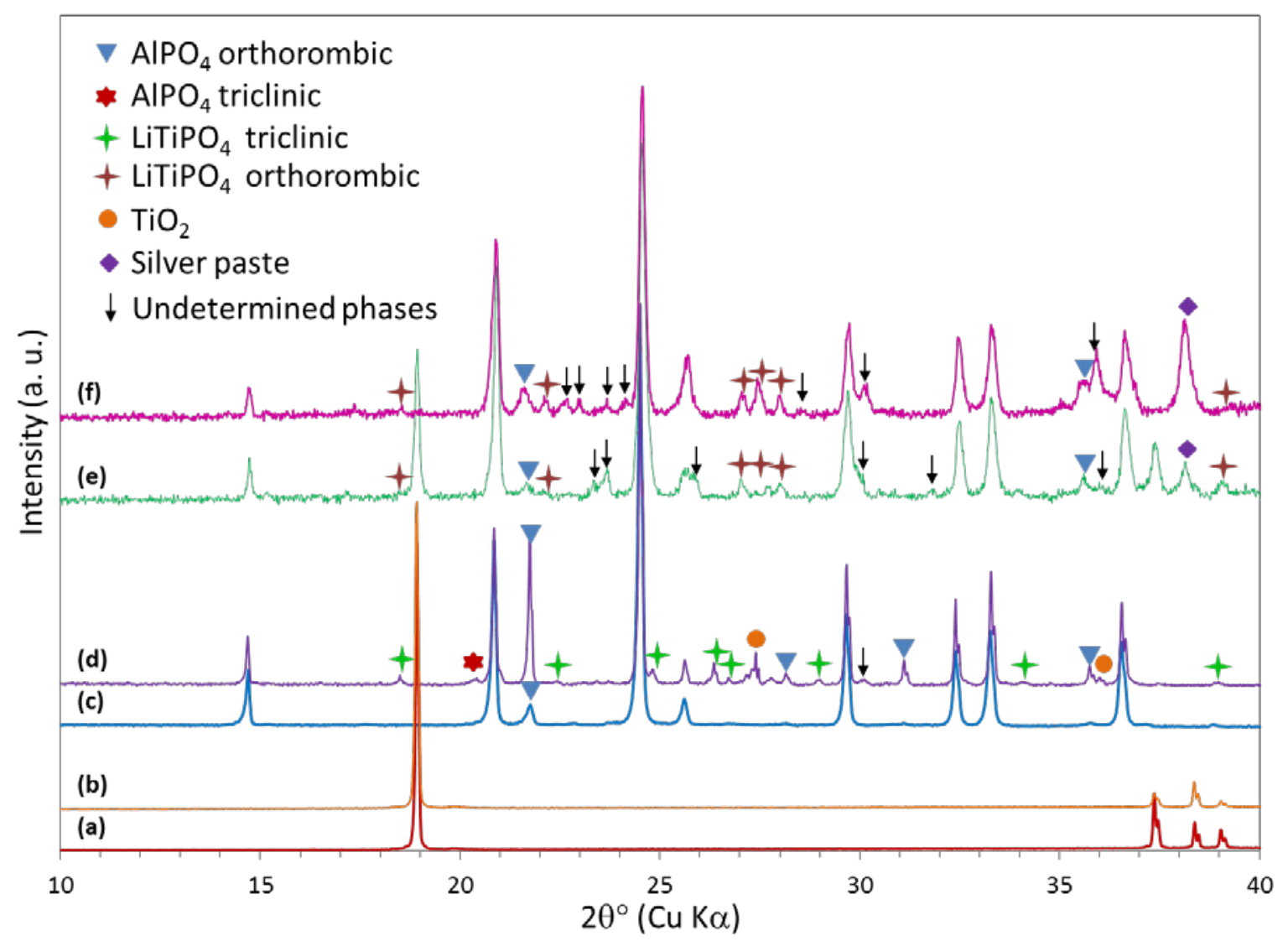

Fig. 5. XRD patterns of (a) LCO initial powder, (b) LCO pellet after conventional sintering at $1040^{\circ} \mathrm{C}$ under argon, (c) LATP initial powder, (d) LATP pellet after conventional sintering at $1050^{\circ} \mathrm{C}$ under air, (e) System 1 (LCO/LATP/LCO), (f) System 2 (composite LATP+LCO / LATP / composite LATP+LCO).

To verify the chemical reactivity of LCO and LATP during FS, XRD analyses were performed on the two multi-systems: System 1 (Fig.5-e) and System 2 (Fig.5-f) and compared to the analyses obtained on the pristine powders of LCO (Fig.5-b) and LATP (Fig.5-c). LCO and LATP pellets obtained by conventional sintering at $1040{ }^{\circ} \mathrm{C}$ under argon (Fig.5-b) and at $1050^{\circ} \mathrm{C}$ under air (Fig.5-d) respectively, are also displayed. First of all, it appears that LATP sintered pellet presents some impurities of $\mathrm{AlPO}_{4}, \mathrm{LiTiPO}_{4}$ and $\mathrm{TiO}_{2}$. These impurities are classically reported in the 
literature for LATP conventional sintering. ${ }^{(42)}$ On the opposite, LCO sintered pellet does not show apparent extra phases on the diagram in Fig. 5-b after CS. System 1 XRD patterns (Fig. 5-e) present few impurities of $\mathrm{TiO}_{2}$, orthorhombic and triclinic $\mathrm{AlPO}_{4}$, orthorhombic and triclinic $\mathrm{LiTiPO}_{4}$. However, most of these impurities comes from the LATP structural evolution after high temperature treatment, as seen on Erreur ! Source du renvoi introuvable.-d. Some unidentified phases appear on the diagrams of System 1 and 2 (arrows on Fig.5-e and f). They may come from a contamination of the stainless steel ball milling media. No mixed compounds between LCO and LATP were clearly observed on the XRD patterns. It illustrates that the short duration of FS limits chemical reactions between the components of a multi-layer system in comparison with conventional sintering performed on the same materials. ${ }^{(43)(44)}$

System 1 using LCO as electrodes demonstrates how electrochemical considerations can allow FS in a multi-layer system containing pure $\mathrm{Li}^{+}$ionic conductors. Optimized conditions are however still to be determined, as LATP exhibited significant densification close to the LATP-LCO interface but high porosity in the center area. Besides, delamination and cracks that happen during cooling possibly due to both differences in thermal properties of LCO and LATP and low interfacial bounding are strongly detrimental to electrochemical performances. For instance, we observed by impedance spectroscopy that the overall impedance of the multi-layered system appeared higher and more distributed in frequency after FS than before FS, as a result of the interfacial delamination.

That is why, in order to limit thermomechanical stresses at the LCO / LATP interface, a composite electrode made up of 28 vol $\%$ LCO +72 vol $\%$ LATP, instead of pure LCO, was used in System 2 (Fig. 6-a). In that case, using similar conditions than for System 1, a Flash occurred after only 13 s (Fig. 6-b): the composite electrodes enabled the reversible electrochemical reaction (Eq. 
2) and thus the current flow through the layer of LATP ionic conductor. Herein, the reversible electrochemical reaction did not only occur at the interface between the layers but at each LCO / LATP interface within the composite layer.

(a)

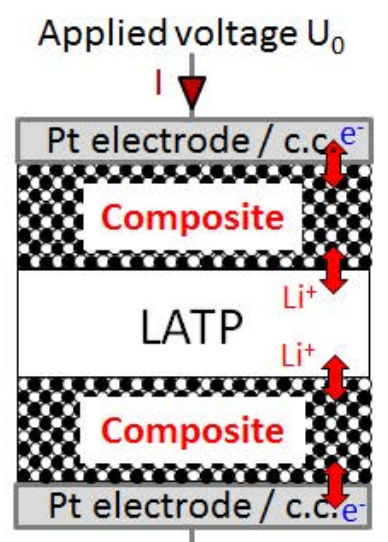

(c)

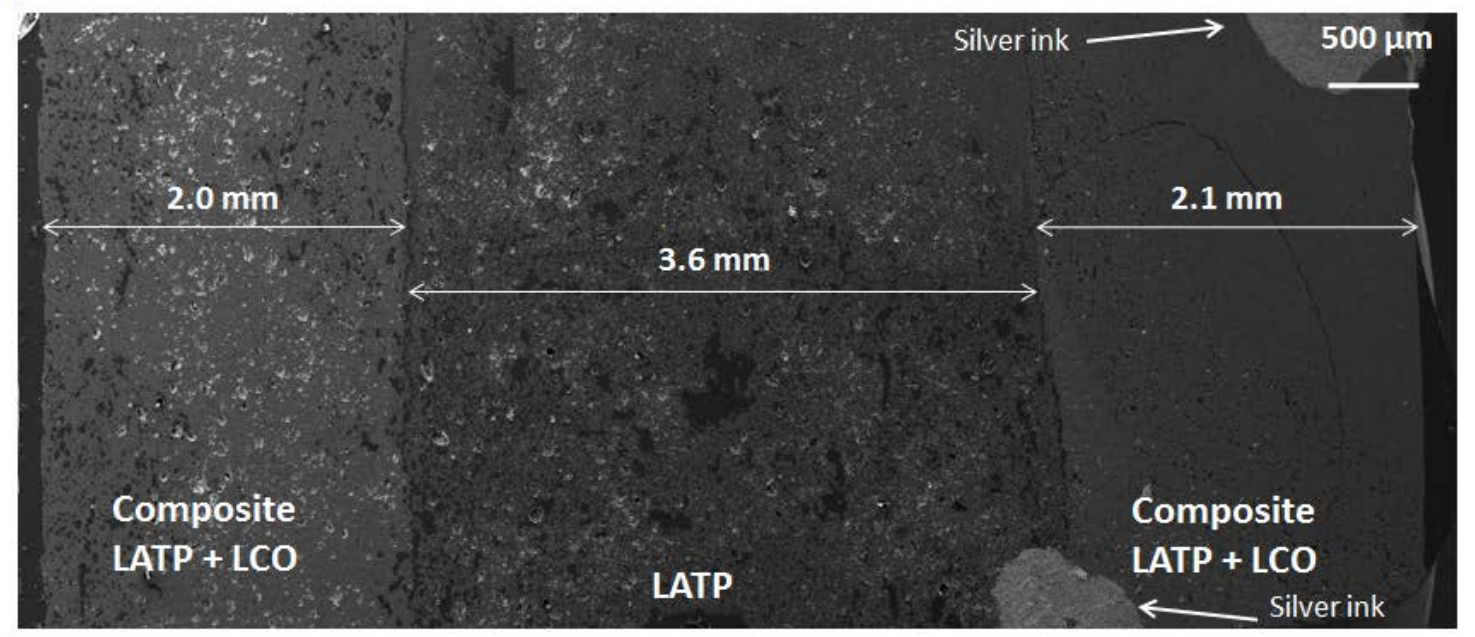

(d)

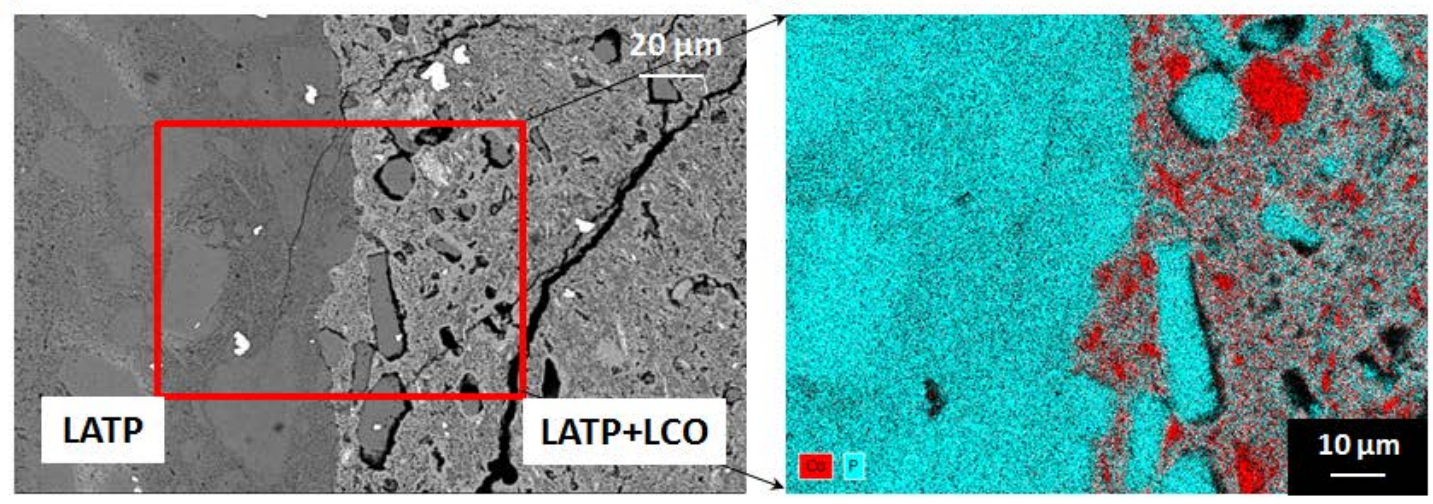

(b)

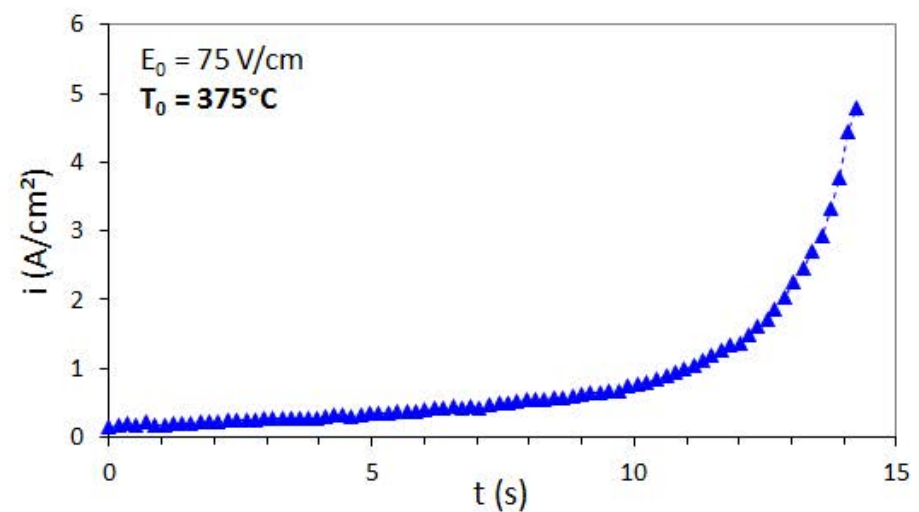


Fig. 6. FS on System 2: composite LCO+LATP / LATP / composite LCO+LATP: (a) Scheme of the cell and charge carriers exchange; (b) Current density vs time under $75 \mathrm{~V} . \mathrm{cm}^{-1}$ at $\mathrm{T}_{0}=375{ }^{\circ} \mathrm{C}$ (isothermal); (c) SEM image of the composite / LATP interface (SE- $15 \mathrm{kV}$ ); (d) SEM image zoom of the interface; (e) EDS map of phosphorus (blue) and cobalt (red).

The SEM images (Fig. 6-c and d) reveal that the microstructure at the interface between LATP and the LCO+LATP composite presents some cracks but no delamination, unlike System 1. The use of this composite led to lower mechanical stresses at the interface between the layers. As for System 1, EDS maps show no significant inter-diffusion between the chemical elements of LATP (phosphorus) and LCO (cobalt), even within the composite where the particles of each phase are clearly distinguished. The XRD patterns displayed in Erreur ! Source du renvoi introuvable.-f have no evidence of any mixed compounds resulting from the chemical reactivity between LCO and LATP, even if small amounts of some extra phases $\left(\mathrm{TiO}_{2}, \mathrm{AlPO}_{4}, \mathrm{LiTiPO}_{4}\right)$ can be observed. As well as for System 1, these phases seem to come from the degradation of the LATP phase, which generally occurs above $1050^{\circ} \mathrm{C}$. We can notice that the $\mathrm{LiCoO}_{2}$ phase does not appear on the XRD pattern of System 2 (Erreur ! Source du renvoi introuvable.-f), probably due to the low LCO content in the composite (almost half of the surface exposed to XRD beam, i. e. $<14$ vol\%).

The relative density calculated from thickness measurement on the SEM image (Fig. 6-c) was estimated at $78^{+} /-2 \%$ for the pure LATP layer, and $75^{+} /-2 \%$ for each composite layer. That shows a significant improvement of densification compared to System 1, even if residual porosity is observed and the microstructure remains heterogeneous. 


\section{Conclusion}

Through this work, we have demonstrated the feasibility of the Flash Sintering of ceramics multilayer systems composed of a pure $\mathrm{Li}^{+}$cationic conductor in between two layers of an electrode made of an active material of battery, based on the reversible electrochemical reaction at their interfaces.

Firstly, the possibility of performing FS on the mixed $\mathrm{Li}^{+}$ionic / electronic conductor (MIEC) LCO was highlighted with the strong advantage of considerably reducing the furnace temperature (i.e. $375{ }^{\circ} \mathrm{C}$ compared to $1040{ }^{\circ} \mathrm{C}$ for the CS pellet). For a MIEC the only necessary condition for the flash seems to be that the electronic conductivity is thermally activated. However, the process parameters have to be further optimized to achieve high density. An increase of the current density and the application of a plateau are the first options to be studied.

Secondly, LCO has proven to be a suitable electrode material enabling FS for LATP cationic conductor. The flash event occurred with both studied multi-layer systems, i.e. LATP sandwiched between two LCO powder layers as electrodes; and LATP sandwiched between two LCO+LATP composite powder electrodes. It has been shown that in the composite case a higher relative density is reached and the mechanical stresses are significantly reduced, thus preventing large delamination. These results open the path of one shot flash sintering of a functional electrochemical systems made of multimaterials such as All Solid-State Ion Batteries at relatively low temperature, and in short time, promising low interfacial reactivity which is one of the main drawbacks of multimaterial sintering. 


\section{REFERENCES}

(1) Cologna M, Rashkova B, Raj R. Flash sintering of nanograin zirconia in $<5 \mathrm{~s}$ at $850{ }^{\circ} \mathrm{C}$. J. Am. Ceram. Soc. 2010;93:3556-3559.

(2) Steil MC, Marinha D, Aman Y, Gomes JRC, Kleitz M. From conventional ac flashsintering of YSZ to hyper-flash and double flash. J. Eur. Ceram. Soc.2013;33:20932101.

(3) Todd RI, Zapata-Solvas E, Bonilla RS, Sneddon T, Wilshaw PR. Electrical characteristics of flash sintering: thermal runaway of Joule heating. J. Eur. Ceram. Soc.2015;35(6):1865-1877.

(4) Francis JSC, Raj R. Flash-Sinterforging of Nanograin Zirconia: Field Assisted Sintering and Superplasticity. J. Am. Ceram. Soc. 2012;95(1):138-146.

(5) Ren K, Wang Q, Lian Y, Wang Y. Densification kinetics of flash sintered 3 mol $\% \mathrm{Y}_{2} \mathrm{O}_{3}$ stabilized zirconia. J. Alloys Compd. 2018;747:1073-1077.

(6) Carvalho SGM, Muccillo ENS, Muccillo R.AC Electric Field Assisted Pressureless Sintering Zirconia: 3 mol\% Yttria Solid Electrolyte. Physica Status Solidi (a) 2018;215(6):1700647.

(7) Cologna M, Prette ALG, Raj R. Flash-sintering of cubic yttria-stabilized zirconia at 750 ${ }^{\circ} \mathrm{C}$ for possible sse in SOFC manufacturing. J. Am. Ceram. Soc. 2011;94(2):316-319.

(8) Downs JA, Sglavo VM. Electric Field Assisted Sintering of Cubic Zirconia at $390{ }^{\circ} \mathrm{C} . J$. Am. Ceram. Soc. 2013;96(5):1342-1344. 
(9) Biesuz M, Pinter L, Saunders T, Reece M, Binner J, Sglavo V, Grasso S. Investigation of Electrochemical, Optical and Thermal Effects during Flash Sintering of 8YSZ. Materials 2018;11(7):1214.

(10) Vendrell X, Yadav D, Raj R, West AR. Influence of flash sintering on the ionic conductivity of 8 mol\% yttria stabilized zirconia. J. Eur. Ceram. Soc. 2018;39(4):13521358.

(11) Yoshida H, Sakka Y, Yamamoto T, Lebrun J-M, Raj R. Densification behaviour and microstructural development in undoped yttria prepared by flash-sintering. J. Eur. Ceram. Soc. 2014;34(4):991-1000.

(12) Hao X, Liu Y, Wang Z, Qiao J, Sun K. A novel sintering method to obtain fully dense gadolinia doped ceria by applying a direct current. J. Power Sources 2012;210:86-91.

(13) Gaur A, Sglavo VM. Densification of $\mathrm{La}_{0.6} \mathrm{Sr}_{0.4} \mathrm{Co}_{0.2} \mathrm{Fe}_{0.8} \mathrm{O}_{3}$ ceramic by flash sintering at temperature less than $100^{\circ} \mathrm{C}$. J. Mater. Sci. 2014;49(18):6321-6332.

(14) Shomrat N, Baltianski S, Dor E, Tsur Y. The influence of doping on flash sintering

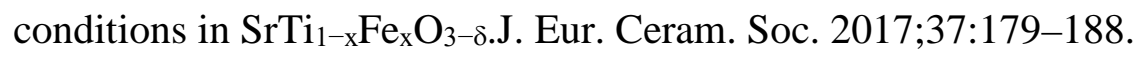

(15) Prette ALG, Cologna M, Sglavo VM, Raj R. Flash-sintering of $\mathrm{Co}_{2} \mathrm{MnO}_{4}$ spinel for solid oxide fuel cell applications. J. Power Sources 2011;196(4):2061-2065.

(16) JhaSK, Raj R. The effect of electric field on sintering and electrical conductivity of titania. J. Am. Ceram. Soc. 2014;97(2):527-534.

(17) Muccillo R, Muccillo ENS. Electric field-assisted flash sintering of tin dioxide. J. Eur. Ceram. Soc. 214;34(4):915-923. 
(18) Schmerbauch C, Gonzalez-Julian J, Röder R, Ronning C, Guillon O. Flash Sintering of Nanocrystalline Zinc Oxide and its Influence on Microstructure and Defect Formation. J. Am. Ceram. Soc. 2014;97(6):1728-1735.

(19) Naik KS, Sglavo VM, Raj R. Flash sintering as a nucleation phenomenon and a model thereof. J. Eur. Ceram. Soc. 2014;34(15):4063-4067.

(20) Bichaud E, Chaix J-M, Carry C, Kleitz M, Steil MC. Flash sintering incubation in $\mathrm{Al}_{2} \mathrm{O}_{3} /$ TZP composites. J. Eur. Ceram. Soc. 215;35:2587-2592.

(21) Kok D, Jha SK, Raj R, Mecartney ML Flash sintering of a three-phase alumina, spinel, and yttria-stabilized zirconia composite. J. Am. Ceram. Soc. 2017;100(7):3262-3268.

(22) Yu M, Grasso S, Mckinnon R, Saunders T, Reece MJ. Review of flash sintering: materials, mechanisms and modeling. Advances in Applied Ceramics. 2017;116(1):2460.

(23) Biezus M, Sglavo VM. Flash sintering of ceramics. J. Eur. Ceram. Soc. 2019;39:115143.

(24) Muccillo R, Kleitz M, Muccillo ENS. Flash grain welding in yttria stabilized zirconia. J. Eur. Ceram. Soc. 2011;31:1517-1521.

(25) Francis JCS, Cologna M, Dario M, Raj R. Flash Sintering of Anode-Electrolyte Multilayers for SOFC Applications. J. Am. Ceram. Soc. 2013;93(5):1352-1354.

(26) Caliman LB, Bouchet R, Gouvea D, Soudant P, Steil MC. Flash sintering of ionic conductors: the need of a reversible electrochemical reaction. J. Eur. Ceram. Soc.2016;36:1253-1260. 
(27) Clemenceau T, Andriamady N, Kumar MKP, Badran A, Avila V, Dahl K, Hopkins M, Vendrell X, Marshall D, Raj R. Flash sintering of Li-ion conducting ceramic in a few seconds at $850{ }^{\circ} \mathrm{C}$. Scripta Materialia 2019;172:1-5.

(28) Aboulaich A, Bouchet R, Delaizir G, Seznec V, Tortet L, Morcrette M, Rozier P, Tarascon JM, Viallet V, Dollé MA, New Approach to Develop Safe All-Inorganic Monolithic Li-Ion Batteries, Adv. Eng. Mater. 2011;1(2):179-183.

(29) Delaizir G, Viallet V, Aboulaich A, Bouchet R, Tortet L, Seznec V, Morcrette M, Tarascon JM, Rozier P, Dollé M. The Stone Age Revisited: Building a Monolithic Inorganic Lithium-Ion Battery, Adv. Funct. Mater. 2012;22:2140-2147.

(30) Okumura T, Takeuchi T, Kobayashi $\mathrm{H}$, Application of $\mathrm{LiCoPO}_{4}$ Positive Electrode Material in All-Solid-State Lithium-Ion Battery. Electrochemistry 2014;82(10):906908.

(31) Laptev AM, Zeng H, Bram M, Finsterbusch M, Guillon O. High-pressure field assisted sintering of half-cell for all-solid-state battery. Materials Letters 2019;247:155-158.

(32) Ihrig M, Finsterbusch M, Tsai CL, Laptev AM, Tu C, Bram M, Sohn YJ, Ye R, Sevinc S, Lin S, Fattakhova-Rohlfing D, Guillon O. Low temperature sintering of fully inorganic all-solid-state batteries - impact of interfaces on full cell performance. Journal of Power Sources 2021;482:228905.

(33) Akimoto J, Gotoh Y, Oosawa Y. Synthesis and Structure Refinement of $\mathrm{LiCoO}_{2}$ Single Crystals. J. Solid State Chem. 1998;141(1):298-302. 
(34) Duluard S, Paillassa A, Puech L, Vinatier P, Turq V, Rozier P, Lenormand P, Taberna P-L, Simon P, Ansart F. Lithium conducting solid electrolyte $\mathrm{Li}_{1.3} \mathrm{Al}_{0.3} \mathrm{Ti}_{1.7}\left(\mathrm{PO}_{4}\right)_{3}$ obtained via solution chemistry. J. Eur. Ceram. Soc. 2013;33(6):1145-1153.

(35) Francis JSC, Raj R. Influence of the field and the current limit on flash sintering at isothermal furnace temperatures. J. Am. Ceram. Soc. 2013;96:2754-2758.

(36) Bichaud, E. Frittage «flash» de céramiques sous courant alternative. PhD. Thesis, 2016, Grenoble Alpes Uni.

(37) Cordier A, Kleitz M, Steil MC. Welding of yttrium-doped zirconia granules by electric current activated sintering (ECAS): Protrusion formation as a possible intermediate step in the consolidation mechanism. J. Eur. Ceram. Soc. 2012;32(8):1473-1479.

(38) El Khal H, Relations frittage - microstructure - propriétés électriques des céramiques de type LAMOX. PhD. Thesis, 2017, Grenoble Alpes Uni.

(39) Cordier A, El Khal H, Siebert E, Steil MC. On the role of the pore morphology on the electrical conductivity of porous yttria-stabilized zirconia. J. Eur. Ceram. Soc. 2019;39(7):2518-2525.

(40) Cheng EJ, Taylor NJ, Wolfenstine J, Sakamoto J. Elastic properties of lithium cobalt oxide $\left(\mathrm{LiCoO}_{2}\right)$. J. Asian Ceram. Soc. 2017;5:113-117.

(41) Jackman SD, Culter RA. Effect of microcracking on ionic conductivity in LATP. J. Power Sources. 2012;218:65-72. 
(42) Xiao W, Wang J, Fan L, Zhang J, Li X. Recent Advances in $\mathrm{Li}_{1+{ }_{x}} \mathrm{Al}_{\mathrm{x}} \mathrm{Ti}_{2-\mathrm{x}}\left(\mathrm{PO}_{4}\right)_{3}$ SolidState Electrolyte for Safe Lithium Batteries. Energy Storage Materials. 2019;19:379_ 400.

(43) Nagata K, Nanno T. All solid battery with phosphate compounds made through sintering process. J. Power Sources. 2007;174(2):832-837.

(44) Kato T, Yoshida R, Yamamoto K, Hirayama T, Motoyama M, West WC, Iriyama Y. Effects of sintering temperature on interfacial structure and interfacial resistance for allsolid-state rechargeable lithium batteries. J. Power Sources. 2016;325:584-590. 
TABLE OF CONTENT

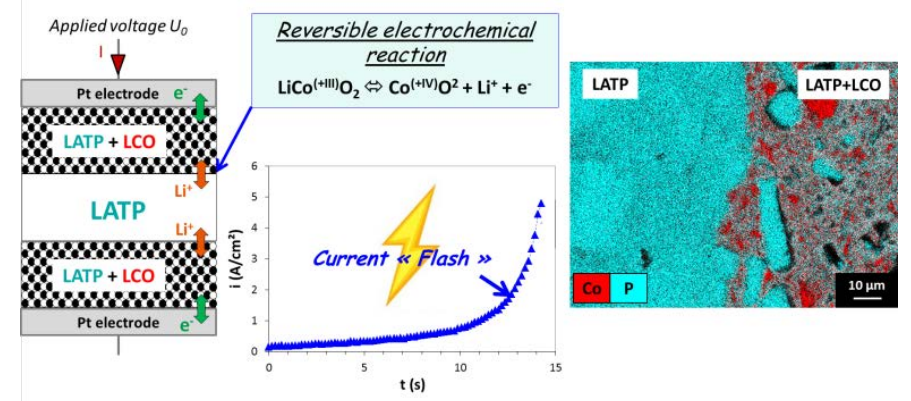




\section{AUTHOR INFORMATION}

\section{Corresponding Author}

*Email: marlu-cesar.steil@grenoble-inp.fr

*Email: renaud.bouchet@grenoble-inp.fr

\section{Author Contributions}

The manuscript was written through contributions of all authors. All authors have given approval to the final version of the manuscript.

\section{Notes}

The authors declare no competing financial interests.

\section{ACKNOWLEDGMENT}

The authors acknowledge financial support from the Centre of Excellence of Multifunctional Architectured Materials “CEMAM” no. ANR-10-LABX-44-01. 